\title{
SOCIOLINGÜÍSTICA DE LA ELISIÓN DE LA DENTAL -/d/- EN MADRID (DISTRITO DE SALAMANCA)
}

Isabel Molina Martos

Universidad de Alcalá isabel.molina@uah.es
Florentino Paredes García

Universidad de Alcalá

florentino.paredes@uah.es

This article analyzes the elision of intervocalic / $/$ / in Madrid (Salamanca district) and provides a social and linguistic description of the dual tendency of this change, conservative in the general context and innovative in the -ado context. Variationist analyses are contrasted and complemented with approaches that bring into the discussion individual contributions, in order to highlight the agentivity of speakers and the performative nature of language. We use statistic correlations and regression analyses to test the influence of 26 variables in the realization of the segment, and to measure the individual impact of the speakers in the innovation.

Key words: sociolinguistics of Madrid, sound change, individual variation

En este artículo se analiza la elisión del fonema dental /d/ en posición intervocálica en Madrid (distrito de Salamanca), con objeto de caracterizar social y lingüísticamente el cambio en su doble tendencia, conservadora en el entorno general e innovadora en el entorno - ado. Se completan y reinterpretan los análisis variacionistas con otros que analizan el aporte individual con el fin de explorar 
una dimensión que evidencie la agentividad de los hablantes y la naturaleza performativa de la lengua en uso. Mediante análisis de correlaciones y análisis de regresión se analiza la incidencia de 26 variables en la realización del segmento y se atiende al impacto individual de los hablantes en la innovación.

Palabras clave: sociolingüística de Madrid, cambio fónico, variación individual

\section{INTRODUCCIÓN}

La investigación sociolingüística en el ámbito hispánico ha experimentado en la dos últimas décadas un importante desarrollo teórico y metodológico. ${ }^{1}$ A su evolución metodológica ha contribuido la consolidación del "Proyecto para el Estudio Sociolingüístico del Español de España y América" (PRESEEA), que surge de la necesidad de contar con un corpus panhispánico de materiales de habla estratificados sociolingüísticamente. El principal objetivo del PRESEEA ha sido aportar a la comunidad científica material sociolingüístico de las comunidades urbanas hispanohablantes con el fin de conocer cada estructura en particular y abordar análisis coordinados que expliquen en qué sentido se orientan las innovaciones panhispánicas y cuáles son los elementos motores que las impulsan.

En Espańa, los equipos de Málaga, Granada, Valencia, Las Palmas de Gran Canaria y Madrid llevan a cabo un análisis multivariable coordinado que examina el impacto de los mismos factores sobre el segmento dental, del que se han considerado tres clases de variantes: $1^{\text {a: }}$ segmento percibido

${ }^{1}$ Este trabajo se inscribe en el proyecto de investigación "Patrones sociolingüísticos y procesos de integración sociolingüística en Madrid” (Ref. FFI2011-29189-C05-02), financiado por el Ministerio de Ciencia e Innovación de España. 
como fricativo o como aproximante sin ruido $\left[\partial_{\tau}\right] ; 2^{\mathrm{a}}$ : segmento aproximante debilitado [ $\left.{ }^{\partial}\right]$; y $3^{\text {a }}$ : elisión [ø] con percepción de hiato, diptongo o vocal de duración variable (Villena 2012: 956). Para el análisis se elaboró una hoja de codificación con 25 variables independientes, de las cuales 14 son factores lingüísticos, 7 factores estilísticos y 4 factores sociológicos. ${ }^{2}$

En la actualidad, desde la sociolingüística se afronta una reflexión sobre la capacidad que tienen los hablantes de intervenir con su práctica lingüística individual en estructuras sociales complejas. Desde este nuevo punto de vista, la variación ya no es mero reflejo de la estructura social, sino también "un recurso para poner en práctica determinadas acciones, cualidades o posiciones que conforman un entramado de significados microsociológicos” (Eckert 2009). La Sociolingüística de la Tercera Ola propone una visión del comportamiento lingüístico en el marco de una teoría social en la que el estudio de la lengua forma parte de una reflexión global sobre el individuo. La variación también se interpreta en términos locales, lo que permite comprender con mayor flexibilidad y de forma más matizada las opciones lingüísticas de los hablantes. ${ }^{3}$

2 Cf. "Análisis de la /d/ intervocálica. Propuesta de codificación", la hoja de codificación de la /d/ intervocálica con las 26 variables (1 dependiente y 25 independientes), elaborada por los equipos PRESEEA para el análisis coordinado de la obstruyente oclusiva dental (<preseea. linguas.net/metodologia $>$ ).

3 Desde esta perspectiva, se entiende que las formas lingüísticas no remiten directamente a categorías sociales, sino indirectamente, a través de elementos realizados discursivamente, como la toma de posiciones específicas. El hablante es un actor social en el discurso, donde puede posicionarse con respecto a cualquier dimensión del contexto sociocultural y realizar cosas con palabras, como crear significado social en diferentes niveles de indexicalidad. Esta nueva perspectiva conlleva la aplicación de metodologías de análisis que combinen los tradi- 
En este estudio se completan y reinterpretan los análisis variacionistas con otros que analizan el aporte individual con el fin de explorar una dimensión que evidencie la agentividad de los hablantes y la naturaleza performativa de la lengua en uso. Investigaciones previas ${ }^{4}$ han demostrado cuantitativamente que la variación de la dental en las ciudades españolas está fuertemente condicionada por factores lingüísticos como la categoría gramatical de la palabra o el morfema en que aparece, de modo que en algunas comunidades la elisión se registra en el sufijo de los participios, pero apenas se desarrolla en las raíces léxicas.

La difusión de la elisión se caracteriza sociolingüísticamente como un "cambio desde abajo", que comenzó extendiéndose a todos los contornos fónicos entre los grupos de bajo estatus. El origen social de la innovación provocó una reacción en contra de las élites: un movimiento de retracción que consistió en retener la /d/ en todos los contextos donde el hablante interpreta que puede perderse. En Madrid, el proceso tiene características distintas a las que se han descrito en Granada, Málaga o Las Palmas, ${ }^{5}$ pues la elisión retrocede en todos los contextos fónicos excepto en -ado,

cionales factores macrosociológicos (sexo, edad, nivel educativo, clase social...) con categorías intermedias e individuales. Con ello se persigue evidenciar la capacidad que el hablante como individuo tiene de intervenir sobre la estructura social, una posibilidad que en la sociolingüística tradicional queda difuminada tras las grandes categorías sociológicas.

${ }^{4}$ Cf. Gómez Molina y Gómez Devís 2010; Gómez Molina 2013; Moya et al. 2012; Samper et al. 2010; Samper et al. 2011, 2011b; Villena Ponsoda et al. 2011, Villena 2012.

5 La jerarquía entre las restricciones de fidelidad y de marcación explica por qué en algunas variedades la elisión no marcada de segmentos es más frecuente que en otras, y por qué razón tiende a desplazarse a la terminación de las palabras (cf. Martín Butragueño 2002; Samper 2011; Villena 2012). 
donde su frecuencia, en lugar de reducirse, aumenta. Los sectores sociales más influyentes en Madrid pronuncian -ao <-ado incluso en situaciones formales, y como son los que marcan la tendencias lingüísticas, es previsible que su comportamiento se difunda a otras zonas de la ciudad y a los pueblos de la región (Molina 2011).

Teniendo en cuenta esta caracterización general del cambio, se han establecido siete hipótesis de investigación.

a) Hipótesis sobre el entorno general: 1) el barrio de Salamanca de Madrid es conservador en sus realizaciones de la dental; 2) los sectores sociales que favorecen la tendencia conservadora son los hablantes de instrucción alta y las mujeres; 3) en el entorno general, la incidencia de los factores lingüísticos es mayor que la de los factores socioestilísticos; 4) la tendencia a la elisión en el barrio de Salamanca se ajusta más al patrón de un cambio fónico que al de un cambio por difusión léxica.

b) Hipótesis sobre el entorno restringido -ado: 5) en Madrid, la elisión de la dental no es un cambio general ni social ni lingüísticamente extendido, sino una innovación restringida al entorno -ado; 6) la elisión en el entorno - ado es un cambio consciente, que funciona en esta comunidad de habla como marcador, esto es, una variable sociolingüística que covaría con factores sociales y estilísticos; 7) la variable en el entorno -ado supone un movimiento de convergencia con las hablas castellanas septentrionales.

En relación con las hipótesis, en este trabajo se han planteado cinco objetivos: 1) caracterizar social y lingüísticamente el cambio en su tendencia general conservadora; 2) demostrar estadísticamente el carácter 
innovador del cambio en el entorno -ado en el barrio de Salamanca; 3) caracterizar social, estilística y lingüísticamente la innovación en el entorno -ado; 4) analizar el impacto individual de los hablantes del barrio de Salamanca en la innovación, incorporándolos en el análisis como variables independientes por su capacidad de influir sobre el proceso; 5) valorar la antigüedad o novedad del cambio en el entorno restringido a partir de su estratificación por grupos de edad.

\section{Análisis cuantitativo de la elisión de la Dental /d/}

El corpus que se ha usado para el análisis del fonema consta de cincuenta y cuatro entrevistas semidirigidas realizadas casi todas entre 2001 y 2002 a una muestra sociológicamente representativa del distrito de Salamanca madrileńo. Los sujetos fueron seleccionados mediante un muestreo por cuotas de asignación uniforme en función del sexo, la edad y el nivel de instrucción, con tres sujetos por casilla. Para el estudio se analizaron todos los casos de /d/ intevocálica en cinco minutos del comienzo de la entrevista, cinco del medio y otros cinco del final.

El análisis se ha estructurado en cuatro etapas. En primer lugar, se realiza un análisis de todo el corpus dirigido a determinar cuáles son los entornos más favorables a la elisión. El propósito es definir contextos lingüísticos cada vez más acotados hasta determinar en qué entornos y con qué restricciones se desarrolla la elisión en Madrid (cf. \$2.1). En segundo lugar, se hace un análisis de correlaciones bivariantes para calcular la posible incidencia de cada una de las 25 variables independientes (lingüísticas, estilísticas y sociales) sobre la realización de la dental. A las variables 
sociales que mantienen una correlación positiva con la elisión, se les aplica un análisis de correlaciones trivariantes que determina cómo interactúan sobre la dental las variables sociales tomadas de dos en dos (cf. \$2.2). Si en $\$ 2.1$ y $\$ 2.2$ se trabaja con macrocategorías sociales, el tercer análisis bivariante incorpora el estudio de la variación individual tomando cada hablante de la muestra del barrio de Salamanca como una variable independiente con capacidad de influir sobre el cambio (cf. \$2.3). El estudio se cierra con el análisis escalonado de regresión múltiple (cf. \$2.4) que permite determinar el peso conjunto de las variables incidentes en la elisión del fonema, la jerarquía entre ellas y el peso de cada variante.

\subsection{Análisis secuencial del corpus: cuatro entornos que restringen progresivamente el contexto más favorable a la elisión}

Para un análisis de la variable -/d/- que explique el comportamiento de los madrileńos del barrio de Salamanca, se han calculado las probabilidades de elisión en cuatro entornos fónicos cada vez más restrictivos que arrojan valores cada vez más altos de elisión. El primer análisis, realizado sobre todo el corpus de datos (corpus general), contiene casos de /d/ intervocálica ${ }^{6}$ en cualquier contexto (además, rodea, lado, rápido, navidad, ordenador). Incluye 5460 ocurrencias del segmento dental. El análisis del segundo corpus se limita a los casos de palabras paroxítonas en los que

6 Tras la corrección de errores, se han excluido los casos en los que a /d/ le precede o sigue una paravocal, al corroborarse que en ese contexto la conservación por parte de los madrileños es categórica; estos datos coinciden con los de otras investigaciones sobre el español (Alba 1999:7). 
la $d$ va precedida de una vocal acentuada (sido, todo, cada, vida, estado); consta de 4163 casos. El tercer análisis solo incluye los casos en los que el segmento donde aparece la dental tiene valor morfemático (leido, llegado, congeladas) y se excluyen los casos en los que la dental forma parte de un lexema (todo, cada, modo, lado); este corpus está constituido por 1895 casos. El último corpus solo incluye palabras en que la dental forma parte de la terminación -ado; consta de 903 casos.

El análisis escalonado de los cuatro entornos (tabla 1), permite ver el progreso de la elisión, más acusada a medida que se restringe el contexto fónico; así, se pasa de un $14.29 \%$ en el entorno general a un $17.44 \%$ en el restringido, un $27.65 \%$ cuando la dental forma parte del morfema y un $55.15 \%$ en la terminación-ado.

Tabla 1. Realización del segmento /d/ según los entornos

\begin{tabular}{lrrrrrrrr}
\hline & \multicolumn{2}{c}{ Ent. general } & \multicolumn{2}{c}{ Ent. restringido } & \multicolumn{2}{c}{ Ent. morfemático } & \multicolumn{2}{c}{ Entorno -ado } \\
& \multicolumn{1}{c}{$\mathbf{N}$} & \multicolumn{1}{c}{$\%$} & \multicolumn{1}{c}{$\mathbf{N}$} & \multicolumn{1}{c}{$\%$} & \multicolumn{1}{c}{$\mathbf{N}$} & \multicolumn{1}{c}{$\%$} & \multicolumn{1}{c}{$\mathbf{~ N}$} & \multicolumn{1}{c}{$\%$} \\
\hline Elisión & 780 & 14.29 & 726 & 17.44 & 524 & 27.65 & 498 & 55.15 \\
Realización plena & 4245 & 77.75 & 3072 & 73.79 & 1237 & 65.28 & 349 & 38.65 \\
Realización debilitada & 435 & 7.97 & 365 & 8.77 & 134 & 7.07 & 56 & 6.20 \\
Total & 5460 & 100.00 & 4163 & 100 & 1895 & 100.00 & 903 & 100.00 \\
\hline
\end{tabular}

La figura 1 ilustra cómo en el contexto más restrictivo (-ado) el patrón conservador se invierte, de manera que la elisión, que en el contexto general presenta frecuencias relativamente bajas, en -ado supera a la conservación de la dental (55.15\%), sumando la realización plena y la debi- 
litada. ${ }^{7}$ Se trata de un porcentaje muy elevado si se tiene en cuenta que la madrileña es una comunidad fonéticamente conservadora y especialmente el barrio de Salamanca, donde el comportamiento en relación con el segmento que estudiamos ha sido tradicionalmente conservador. De esta manera, resulta evidente que en la comunidad madrileña el entorno más propicio a la elisión es -ado, sobre todo cuando se trata de un participio, y que ha de ser este el entorno que haya de tenerse en cuenta en el estudio del cambio en esta comunidad.

Figura 1. Porcentaje de las realizaciones de /d/ según los entornos

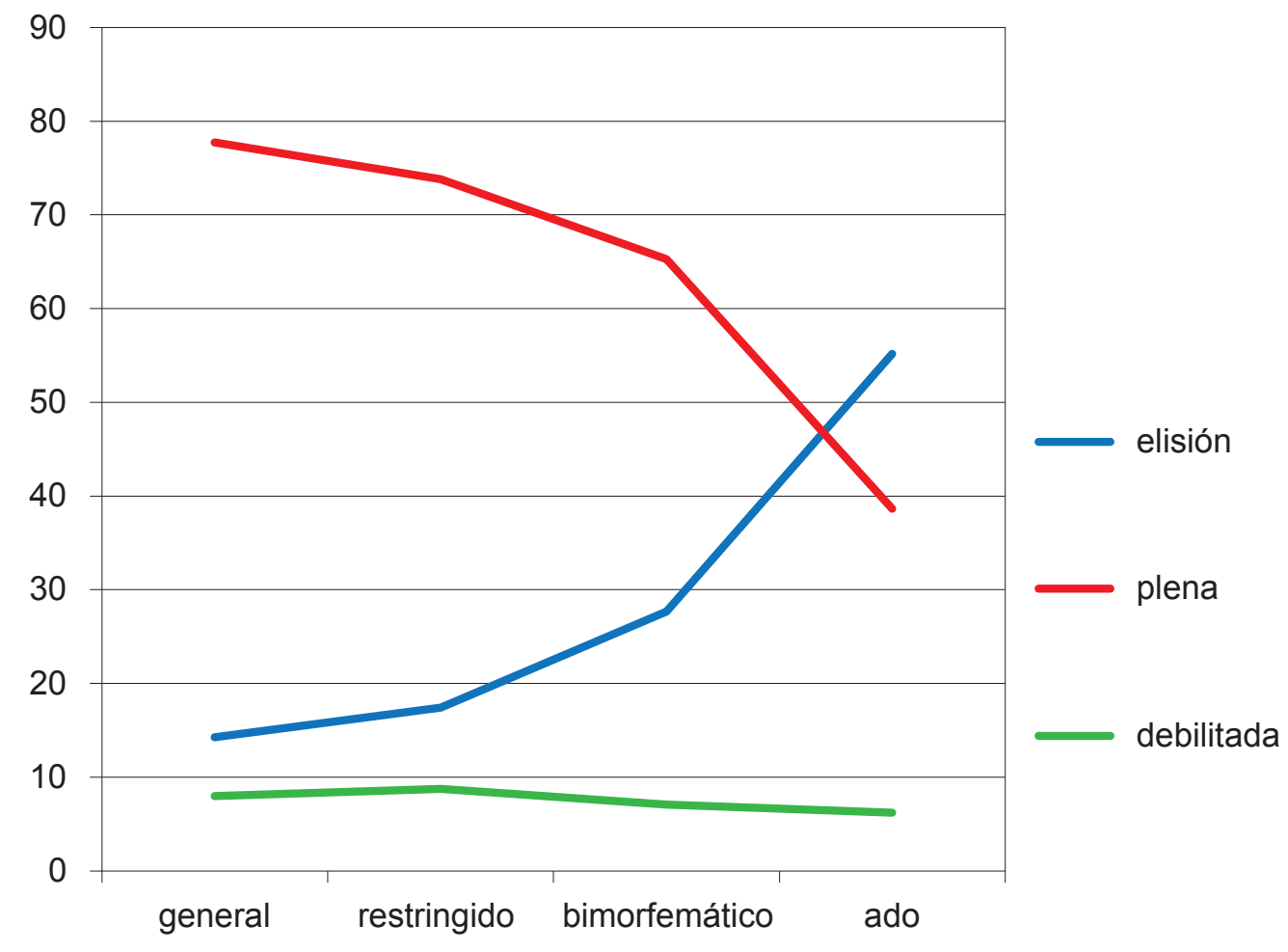

7 Los datos muestran también que el debilitamiento consonántico, además de ser la realización menos frecuente en el habla madrileña, no aparece relacionado con ningún contexto. 
Del primer análisis se deduce que en el barrio de Salamanca de Madrid no hay un cambio lingüístico en marcha en el entorno general, sino un cambio condicionado por la posición del acento y por el carácter morfemático o lexemático del segmento donde aparece la /d/. En relación con las otras ciudades españolas estudiadas en el PRESEEA, Madrid se sitúa junto con las comunidades de habla conservadoras (Gómez Molina, Molina y Paredes 2012), casi en la misma posición que Valencia si se consideran todos los casos de $d$ intervocálica, pero más adelantada que esta en el entorno -ado. La explicación debe buscarse en la confluencia de factores socioespaciales: la localización geográfica de la ciudad, punto de confluencia de isoglosas entre las variedades meridionales y septentrionales del castellano peninsular (Molina 2006, 2013), así como en los contactos interdialectales que han tenido lugar históricamente en la capital y siguen produciéndose hasta nuestros días.

\subsection{Análisis de correlaciones bivariantes: la incidencia de las variables independientes en la dental}

En segundo lugar, se realizó un análisis de correlaciones bivariantes sobre el corpus que contiene todos los casos de la dental en todos los entornos (entorno general). Se utilizó el programa SPSS 15.0 para calcular correlaciones bivariantes entre la variable dependiente $/ \mathrm{d} /$ y 25 variables independientes lingüísticas, estilísticas y sociales. Para cada una de las correlaciones bivariantes que resultaron significativas se realizó una tabla de contingencia, que aporta frecuencias absolutas y relativas de cada correlación junto con las pruebas de significación estadística. El análisis 
establece que no hay correlación -no se determinan recíprocamenteentre la realización de la -/d/- y las siguientes siete variables: entorno de la palabra; entorno de la secuencia; categoría léxica; tenor y edad; tenor y estatus; nivel de estudios; y modo de vida. En cambio, sí inciden en la articulación de la -/d/- las 18 variables restantes, diez lingüísticas, cinco estilísticas y dos sociales.

\subsubsection{Variables lingüísticas}

El análisis ha mostrado incidentes en la elisión de la dental las siguientes variables lingüísticas: 1) posición del acento; 2) número de sílabas de la palabra donde aparece la dental; 3) estructura acentual de la palabra; 4) vocal previa y vocal posterior a la dental; 5) categoría gramatical de la palabra donde aparece la dental; 6) homofonía; 7) funcionalidad del lexema de la dental; 8) presencia de la dental en límite morfemático; 9) difusión léxica; y 10) asimilación al turno anterior. Los datos generales de cada una de las variables aparecen en la tabla 2 y se analizan a continuación con más detalle los relevantes. 


\section{Tabla 2. Variables lingüísticas correlacionadas con la realización del segmento /d/ (entorno general) ${ }^{8}$}

\begin{tabular}{|c|c|c|c|c|c|}
\hline & \multirow[t]{2}{*}{ Variantes } & \multicolumn{2}{|c|}{ Elisión } & \multicolumn{2}{|c|}{ Total } \\
\hline & & $\mathbf{N}$ & $\%$ & $\mathbf{N}$ & $\%$ \\
\hline Posición del acento & Precede mediatamente & 0 & 0 & 76 & 1.4 \\
\hline$(\chi 2=233.51(8) ; p=0.000$ & Precede inmediatamente & 729 & 93.5 & 4190 & 76.7 \\
\hline \multirow[t]{3}{*}{ V de Cramer: 0.146, $\mathrm{p}=0.000)$} & Sigue mediatamente & 0 & 0 & 37 & 0.7 \\
\hline & Sigue inmediatamente & 41 & 5.3 & 286 & 5.2 \\
\hline & Sílaba tónica & 10 & 1.3 & 871 & 16 \\
\hline No de sílabas de la palabra & Bisílaba & 216 & 27.7 & 2306 & 42.2 \\
\hline$(\chi 2=107.63(4) ; p=0.000$ & Trisílaba & 364 & 46.7 & 1847 & 33.8 \\
\hline V de Cramer: 0.099, $\mathrm{p}=0.000)$ & Polisílaba & 200 & 25.6 & 1307 & 23.9 \\
\hline Contorno vocálico & $-a d o$ & 498 & 55.1 & 903 & 16.54 \\
\hline$(\chi 2=1514.892(22) ; p=0.000$ & $-o d a$ & 32 & 17.3 & 185 & 3.39 \\
\hline \multirow[t]{10}{*}{ V de Cramer: $0.372, p=0.000)$} & $-o d o$ & 102 & 13.2 & 775 & 14.19 \\
\hline & $-a d a$ & 35 & 4.3 & 807 & 14.78 \\
\hline & $-i d o$ & 12 & 1.8 & 658 & 12.05 \\
\hline & -ede & 10 & 6.2 & 161 & 2.95 \\
\hline & $-i d a$ & 2 & 0.7 & 273 & 5.00 \\
\hline & $-e d o$ & 2 & 2.2 & 92 & 1.68 \\
\hline & $-e d a$ & 0 & 0 & 57 & 1.04 \\
\hline & $-u d a$ & 0 & 0 & 17 & 0.31 \\
\hline & $-u d o$ & 0 & 0 & 12 & 0.22 \\
\hline & resto & 87 & 5.7 & 1520 & 27.84 \\
\hline Estructural acentual de la palabra & Proparoxítona & 1 & 0.1 & 180 & 3.3 \\
\hline$(\chi 2=61.283(4) ; p=0.000$ & Paroxítona & 737 & 94.5 & 4742 & 86.8 \\
\hline V de Cramer: 0.075, $\mathrm{p}=0.000)$ & Oxítona & 42 & 5.4 & 538 & 9.9 \\
\hline
\end{tabular}

8 Se indican para cada variable los estadísticos ji cuadrado y V de Cramer, así como las pruebas de significación (p) de ambos. 
Sociolingüística DE LA Elisión De LA DENTAL -/d/-

\begin{tabular}{|c|c|c|c|c|c|}
\hline & \multirow[t]{2}{*}{ Variantes } & \multicolumn{2}{|c|}{ Elisión } & \multicolumn{2}{|c|}{ Total } \\
\hline & & $\mathbf{N}$ & $\%$ & $\mathbf{N}$ & $\%$ \\
\hline Categoría gramatical & Participio & 396 & 50.8 & 1197 & 21.9 \\
\hline$(\chi 2=747.383(14) ; p=0.000$ & Verbo & 12 & 1.5 & 704 & 12.9 \\
\hline \multirow[t]{6}{*}{ V de Cramer: 0.262, $\mathrm{p}=0.000)$} & Nombre & 65 & 8.3 & 1320 & 24.2 \\
\hline & Adjetivo & 117 & 15 & 735 & 13.5 \\
\hline & Pronombre & 44 & 5.6 & 861 & 15.8 \\
\hline & Adverbio & 55 & 7.1 & 285 & 5.2 \\
\hline & Determinante & 77 & 9.9 & 328 & 6 \\
\hline & Otros & 14 & 1.8 & 30 & 0.5 \\
\hline Homofonía & Ausencia de homofonía & 217 & 27.8 & 2129 & 39 \\
\hline \multirow[t]{4}{*}{ V de Cramer: 0.115, $\mathrm{p}=0.000$ ) } & $\begin{array}{l}\text { Homofonía nombre o } \\
\text { adjetivo -participio }\end{array}$ & 208 & 26.7 & 760 & 13.9 \\
\hline & Homofonía adjetivo-nombre & 82 & 10.5 & 502 & 9.2 \\
\hline & Homofonía nombre-verbo & 2 & 0.3 & 39 & 0.7 \\
\hline & Otros casos de homofonía & 271 & 34.7 & 2030 & 37.2 \\
\hline Funcionalidad & La $d$ no es funcional & 750 & 96.2 & 5021 & 92 \\
\hline \multirow[t]{2}{*}{$\begin{array}{l}(\chi 2=35.583(4) ; p=0.000 \\
\text { V de Cramer: } 0.057, p=0.000)\end{array}$} & $\begin{array}{l}\text { Distingue pares de distinta } \\
\text { categoría }\end{array}$ & 29 & 3.7 & 291 & 5.3 \\
\hline & $\begin{array}{l}\text { Distingue pares de igual } \\
\text { categoría }\end{array}$ & 1 & 0.1 & 148 & 2.7 \\
\hline Limite morfemático & $d$ en la estructura léxica & 250 & 32.1 & 3282 & 60.1 \\
\hline$(\chi 2=302.470(4) ; p=0.000$ & $d$ morfemática & 530 & 67.9 & 2173 & 39.8 \\
\hline V de Cramer: 0.166, $\mathrm{p}=0.000$ ) & otros & 0 & 0 & 5 & 0.1 \\
\hline Difusión léxica & vida & 0 & 0 & 145 & 2.7 \\
\hline$(\chi 2=370.565(18) ; p=0.000$ & además & 35 & 4.5 & 114 & 2.1 \\
\hline \multirow[t]{6}{*}{ V de Cramer: 0.184, $\mathrm{p}=0.000$ ) } & todavia & 4 & 0.5 & 21 & 0.4 \\
\hline & cada & 0 & 0 & 98 & 1.8 \\
\hline & nada & 22 & 2.8 & 412 & 7.5 \\
\hline & quedar & 13 & 1.7 & 175 & 3.2 \\
\hline & poder & 12 & 1.5 & 333 & 6.1 \\
\hline & todo núcleo & 40 & 5.1 & 528 & 9.7 \\
\hline
\end{tabular}




\begin{tabular}{llrrrr}
\hline & \multicolumn{1}{c}{ Variantes } & \multicolumn{2}{c}{ Elisión } & \multicolumn{2}{c}{ Total } \\
& & $\mathbf{N}$ & \multicolumn{1}{c}{$\%$} & \multicolumn{1}{c}{$\mathbf{N}$} & \multicolumn{1}{c}{$\%$} \\
\hline & todo modificador & 93 & 11.9 & 398 & 7.3 \\
& otros & 561 & 71.9 & 3236 & 59.3 \\
Asimilación al turno anterior & En el turno anterior no hay $d$ & 662 & 84.9 & 4599 & 84.2 \\
$(\chi 2=15.493(4) ; \mathrm{p}=0.004 ;$ & $\begin{array}{l}\text { En el turno anterior hay } d \\
\text { elidida }\end{array}$ & & & & \\
V de Cramer: 0.38, p =0.004) & En el turno anterior hay d & 45 & 172 & 3.2 \\
& realizada & 83 & 10.6 & 689 & 12.6 \\
& & 780 & 100 & 5460 & 100 \\
\hline
\end{tabular}

El análisis muestra que la realización de -/d/- está correlacionada con la posición que ocupa la sílaba que contiene la dental en relación con el acento de la palabra. La tabla 2 indica cómo la elisión se ve favorecida solo cuando el acento precede inmediatamente a la $d$, contexto que concentra el 93.5\% de todos los casos de elisión (729 ocurrencias de elisión en palabras como todo, pescado o llegado). Los demás entornos son restrictores de la elisión: la $d$ no desaparece nunca cuando precede mediatamente al acento (rápido, pirámide) ni cuando sigue mediatamente (adaptable, adelante). Cuando la dental está situada a una sílaba de distancia del acento, los casos de elisión se produjeron una vez en adaptados, dos en todavía y el resto en además, posiblemente por la erosión fonética a que se ve sometida esta palabra en su uso como marcador discursivo. En cuanto a la situación de la dental en sílaba tónica, los quince casos de elisión de nuestro corpus ocurren exclusivamente en joder cuando se utiliza como interjección, pero nunca se elide si se utiliza como verbo. 
El número de sílabas de la palabra también es un factor asociado a la realización de la $d$. La elisión es más frecuente en las palabras trisílabas (46.7\%) que en las bisílabas (27.7\%) o en las polisílabas (25.6\%) o, de otro modo, si la palabra tiene poco cuerpo fónico, la elisión de $d$ se ve condicionada para evitar problemas de identificación de la unidad (restricción de fidelidad). Ya se señaló en las hipótesis de la investigación que la posición del acento en la palabra está directamente relacionada con nuestra variable, pues la elisión se produce sobre todo en palabras paroxítonas (94.5\%), muy pocas veces en palabras oxítonas (5.4\%) y apenas nunca en las proparoxítonas $(0.1 \%)$. Ahora bien, la frecuencia de palabras paroxítonas en español, y por consiguiente en nuestro corpus, es muy superior (86.8\%), a la de oxítonas (9.9\%) y proparoxítonas (3.3\%).

Las vocales que preceden y siguen a la dental determinan en gran medida la elisión. Para determinar el efecto conjunto del entorno vocálico de la dental, se ha creado una variable, el contorno vocálico, que une la vocal que precede a la $d$ y la vocal que sigue para evidenciar cuáles son los contextos vocálicos en los que tiene lugar la elisión, como se muestra en la tabla 2. El contorno vocálico que sin duda favorece la elisión es -ado: el $55.1 \%$ de casos de pérdida de la dental en el barrio de Salamanca se produce en participios o adjetivos del tipo: sentado > sentao, cansado > cansao. Las elisiones en las terminaciones en -oda (17.3\% de elisión) y en -odo (13.2\%) corresponden a toda y todo, pero nunca a sustantivos (boda, modalidad) ni a adjetivos o verbos (incomoda, incómoda).

Respecto a la categoría gramatical, la mayor parte de las elisiones son participios (50.77\%) y adjetivos (15\%): ambas categorías contienen conjuntamente las dos terceras partes de las elisiones. Tras estas, las que más 
la favorecen son el nombre (8.3\%), el adverbio (7.1\%) y el pronombre (5.6\%). En los nombres, la elisión ocurre en los que acaban en -ado, sobre todo si se trata de nombres comunes (lado>lao, mercado>mercao, pescado $>$ pescao, estado $>$ estao), aunque puede llegar a afectar a los nombres propios (Estado $>$ Estao, Preciados $>$ Preciaos). ${ }^{9}$ Entre los adjetivos también predomina la elisión en -ado, aunque esporádicamente puede encontrarse pérdida en la forma femenina (concienciada, congeladas, empeñada, obsesionada). Un entorno vocálico diferente es el de delgaducho, donde la pérdida se explica a partir de la forma sin el sufijo apreciativo (delgado> delgao $>$ delgaúcho). Todos los casos de determinante y de pronombre en que encontramos elisión corresponden a todo o a sus variantes de género y número. En cuanto al verbo, los doce casos de elisión corresponden únicamente a formas del presente de poder: puedo, puedes, puede. La nómina de adverbios en los que hay elisión está encabezada por además, que aglutina 35 de los 55 casos (63.6\%); este alto porcentaje se debe a su uso como marcador discursivo, como ya vimos.

Cuando se cruza la categoría gramatical con el entorno vocálico, quedan claramente identificadas las palabras con más tendencia a la elisión: participios, adjetivos y nombres en -ado; todo como pronombre y determinante y toda como determinante (tabla 3).

9 El carácter coloquial de los términos en algún caso puede favorecer la elisión, como sucede en tinglado, que se pronunció tinglao en las dos ocasiones en que la palabra se registra en nuestro corpus; pero tampoco son refractarios a la pérdida términos más cultos, como visado. Solo anotamos un caso de elisión en un entorno vocálico diferente de -ado, en la palabra navidades, que el hablante emitió en elocución rápida como [naßi’ðaes]. 
Sociolingüística de la elisión De La Dental -/d/-

Tabla 3. Contorno vocálico y categoría gramatical (elisión en el entorno general)

\begin{tabular}{lrrrrrrrrr}
\hline & Part. & \multicolumn{1}{l}{ V } & \multicolumn{1}{c}{ N } & \multicolumn{1}{c}{ A } & Pron. & Adv. & Det. & otra & Total \\
\hline$-a d o$ & $\mathbf{3 6 3}$ & 0 & $\mathbf{6 1}$ & $\mathbf{8 0}$ & 3 & 5 & 0 & 1 & 513 \\
$-a d a$ & 4 & 0 & 3 & 8 & 14 & 4 & 0 & 5 & 38 \\
- -do & 1 & 0 & 0 & 18 & $\mathbf{2 4}$ & 7 & $\mathbf{5 1}$ & 0 & 101 \\
- -da & 0 & 0 & 0 & 4 & 3 & 0 & $\mathbf{2 6}$ & 0 & 33 \\
$-i d o$ & 12 & 0 & 0 & 1 & 0 & 0 & 0 & 0 & 13 \\
$-i d a$ & 1 & 0 & 0 & 1 & 0 & 0 & 0 & 0 & 2 \\
- -ede & 0 & 10 & 0 & 0 & 0 & 0 & 0 & 0 & 10 \\
- -edo & 0 & 2 & 0 & 0 & 0 & 0 & 0 & 0 & 2 \\
- resto & 15 & 0 & 1 & 5 & 0 & 39 & 0 & 8 & 68 \\
Total & 396 & 12 & 65 & 117 & 44 & 55 & 77 & 14 & 780 \\
\hline
\end{tabular}

La inclusión de la variable Funcionalidad de la dental tenía como objetivo comprobar si la dental se conserva para distinguir pares de unidades léxicas de igual o distinta categoría gramatical, en todo iguales excepto por la presencia o ausencia de la dental. Se trata de casos como bodalboa o todos/tos. De hecho, el análisis de frecuencias indica que esta variable es muy determinante, pues la elisión se produce, casi de forma categórica (96.2\%), cuando la presencia/ausencia de la dental no marca virtualmente diferencia semántica en un par mínimo. No llegan al $4 \%$ los casos en que la dental contribuye a distinguir pares mínimos, sean o no de la misma categoría morfológica. Hay que matizar que, aunque la $d$ se retiene cuando es preciso realizar distinciones semánticas, esa circunstancia sucede muy pocas veces en nuestro corpus. ${ }^{10}$

10 La inmensa mayoría de las palabras que contienen la dental en el corpus no forma par mínimo con otra palabra sin dental: de las 5460 dentales analizadas, solo el 8\% de los casos 
Muy influyente ha resultado también el carácter estructural del fonema, esto es, si forma parte del lema o del morfema. Las dos terceras partes de las elisiones se producen cuando la dental forma parte de un morfema flexivo (67.9\%) y solo un tercio de los casos (32.1\%) se dan cuando la dental está en la raíz léxica.

Por lo que respecta a la frecuencia de uso de las palabras, la mayor parte de los casos de elisión no corresponde a ninguna de las palabras contempladas como muy frecuentes (71.9\%), e incluso en algunas de estas (vida, cada) la conservación de la dental es categórica en el barrio de Salamanca. La elisión aumenta en palabras como todo modificador (11.9\%) y todo núcleo $(5.1 \%) .{ }^{11}$ En cambio, no es frecuente que la $d$ se pierda en estas categorías cuando no forman parte de un sintagma nominal con varios términos: no es característico del barrio de Salamanca encontrar hablantes que digan lo tiene tó en lugar de lo tiene todo. El resto de las palabras presenta frecuencias bajas de elisión que deben explicarse por fonética sintáctica y no por su estructura léxica: además (4.5\%), nada (2.8\%), quedar (1.7\%), poder (1.5\%), todavía $(0.5 \%)$.

Los datos expuestos hasta aquí permiten matizar la hipótesis acerca del tipo de cambio que opera en la comunidad madrileńa. El hecho de que la elisión no aparezca vinculada a la frecuencia de uso de las palabras reduce las posibilidades de que el cambio se produzca por difusión léxica. El caso

sirve a estos fines, mientras que en el $92 \%$ de los casos estudiados ( 5021 palabras) la $\mathrm{d}$ no sirve para distinguir pares.

11 Cuando todal todo forman parte de un sintagma compuesto de varios términos pueden perder la dental por fonética sintáctica (por ejemplo, todo el mundo lo sabe > to-el mundo lo sabe; todas esas cosas > toas-esas cosas). 
madrileño se ajusta mejor al de los cambios fónicos, pero teniendo en cuenta que ni se da por igual en todos los contextos, ni ocurre en todas las palabras en las que el fonema se halla en posición intervocálica, ni la frecuencia de elisión es idéntica en aquellas unidades en que se produce. En este sentido la elisión aparece condicionada por las restricciones de marcación y fidelidad: las primeras actúan conservando la dental lexemática para facilitar la identificación de la unidad léxica; las segundas, facilitando la elisión en aquellos contextos en los que la presencia del segmento no es imprescindible.

Con la variable Asimilación al turno anterior se trata de medir el posible efecto sobre el hablante de la presencia de otras dentales - elididas o conservadas- en el turno anterior, que pueden incitarle a converger fónicamente con la secuencia previa, repitiendo lo que en esta haya sucedido. Sin embargo, en la mayor parte de los casos (4599 casos; 84.2\%) en el turno anterior no hay /d/, luego la posibilidad de que se produzca el esperado efecto convergente solo podría tener lugar en el 15\% restante, pero incluso cuando en el turno anterior hay $d$, el hablante no parece verse condicionado por la manera en que haya sido pronunciada pues, de hecho, se da más elisión cuando en el turno anterior no se elide (10.6\%) que cuando se elide (4.5\%).

\subsubsection{Variables estilísticas}

Las cinco variables estilísticas que inciden en la elisión de la dental son estas: 1) la relación de proximidad entre los interlocutores; 2) el grado de especialización del tema que se trata en la entrevista; 3) el tipo de discurso; 4) el grado de planificación del discurso; y 5) la fase de la interacción. 
Tabla 4. Variables estilísticas correlacionadas con la realización del segmento /d/ (entorno general)

\begin{tabular}{|c|c|c|c|c|c|}
\hline & \multirow[t]{2}{*}{ Variantes } & \multicolumn{2}{|c|}{ Elisión } & \multicolumn{2}{|c|}{ Total } \\
\hline & & $\mathrm{N}$ & $\%$ & $\mathbf{N}$ & $\%$ \\
\hline Tenor y proximidad & Insider & 21 & 2.7 & 183 & 3.4 \\
\hline$(\chi 2=33.620(4) ; p=0.000$ & outsider & 12 & 1.5 & 137 & 2.5 \\
\hline V de Cramer: 0.55, $\mathrm{p}=0.000$ ) & Relación surgida en la entrevista & 747 & 95.8 & 5140 & 94.1 \\
\hline Grado de especialización & No técnico & 615 & 78.8 & 4548 & 83.3 \\
\hline$(\chi 2=40.349(6) ; p=0.000$ & Técnico & 159 & 20.4 & 831 & 15.2 \\
\hline \multirow[t]{2}{*}{ V de Cramer: 0.061, $p=0.000$ ) } & Metalingüístico & 4 & 0.5 & 69 & 1.3 \\
\hline & Otros & 2 & 0.3 & 12 & 0.2 \\
\hline Tipo de discurso & Diálogo & 149 & 19.1 & 1008 & 18.5 \\
\hline$(\chi 2=23.979(10) ; p=0.008$ & Explicativo-expositivo & 355 & 45.5 & 2503 & 45.8 \\
\hline \multirow[t]{4}{*}{ V de Cramer: 0.047, $\mathrm{p}=0.008)$} & Narrativo & 196 & 25.1 & 1385 & 25.4 \\
\hline & Argumentativo & 37 & 4.7 & 279 & 5.1 \\
\hline & Descriptivo & 42 & 5.4 & 274 & 5 \\
\hline & Otros & 1 & 0.1 & 11 & 0.2 \\
\hline Planificación del discurso & Coloquio & 259 & 33.2 & 2138 & 39.2 \\
\hline$(\chi 2=50.563(4) ; p=0.000 ;$ & Pares adyacentes & 306 & 39.2 & 1908 & 34.9 \\
\hline V de Cramer: 0.068, $\mathrm{p}=0.000$ ) & Otros & 215 & 27.6 & 1414 & 25.9 \\
\hline Fases de la interacción & Inicial & 223 & 28.6 & 1862 & 34.1 \\
\hline$(\chi 2=21.238(4) ; p=0.000$ & Intermedia & 265 & 34 & 1815 & 33.9 \\
\hline V de Cramer: 0.044, $p=0.000$ ) & Final & 292 & 37.4 & 1747 & 32 \\
\hline Total & & 780 & 100 & 5460 & 100 \\
\hline
\end{tabular}

La primera de las variables estilísticas examina la posibilidad de que la relación entre los hablantes determine su pronunciación atendiendo a si informante y entrevistador se conocían o no con anterioridad a la entrevista. Pero la mayor parte de los informantes del barrio de Salamanca no 
conocía a los entrevistadores antes de la encuesta y, de hecho, la mayor parte de las ocurrencias analizadas de /d/ (94.1\%) corresponde a entrevistas en las que los interlocutores no se conocían. Es relativo, por tanto, que el 6\% de los casos de relaciones donde había un conocimiento previo a la entrevista sea estadísticamente relevante. Del mismo modo, la variable Especialización del discurso resulta poco explicativa dado que la mayor parte de los temas que normalmente se suscitan en un acto discursivo de estas características puede calificarse como "no especializado" o "no técnico". En la tabla 4 puede comprobarse cómo el 83.3\% de las dentales analizadas (4548) se produjo cuando los temas tratados no eran técnicos. De hecho, aunque esta es la temática que más favorece la elisión (78.8\%), en términos relativos la temática más técnica no parece desfavorecerla (20.4\%).

La variable Tipo de discurso se refiere a la estructura del discurso y a sus parámetros formales y semánticos. Se ha distinguido en las distintas partes de la entrevista el predominio de un discurso explicativo-expositivo, narrativo, argumentativo, descriptivo o dialogado. A priori, se pensó que un estilo dialogado-conversacional sería más propicio a la elisión que el argumentativo, pero de nuevo las características del corpus determinan el predominio de algunos estilos discursivos sobre los otros, y que los resultados del análisis se vean condicionados por su distinto peso en la muestra. Así, el estilo explicativo-expositivo es el que más la favorece, seguido del estilo narrativo y del diálogo.

En cuanto a la variable Planificación del discurso y grado de espontaneidad, determina la incidencia de la forma discursiva sobre la dental, distinguiendo las partes más formales de la entrevista de las más informales, donde el coloquio se produce de forma más espontánea y no obedece 
a la dinámica pregunta-respuesta que caracteriza la entrevista. En la tabla 4 se muestra que la elisión no aumenta en las partes del discurso presuntamente más coloquiales (33.2\%), al contrario, es mayor en la estructura de pares adyacentes característica de la entrevista.

Los resultados más claros se obtienen con la variable Fase de la interacción, que analiza la incidencia del desarrollo de la entrevista en la elisión: se espera que a medida que esta avanza y el hablante se siente más confiado, relaje su discurso y produzca más elisiones, como de hecho ocurre (figura 2).

Figura 2. Porcentaje de elisión según la fase de la entrevista

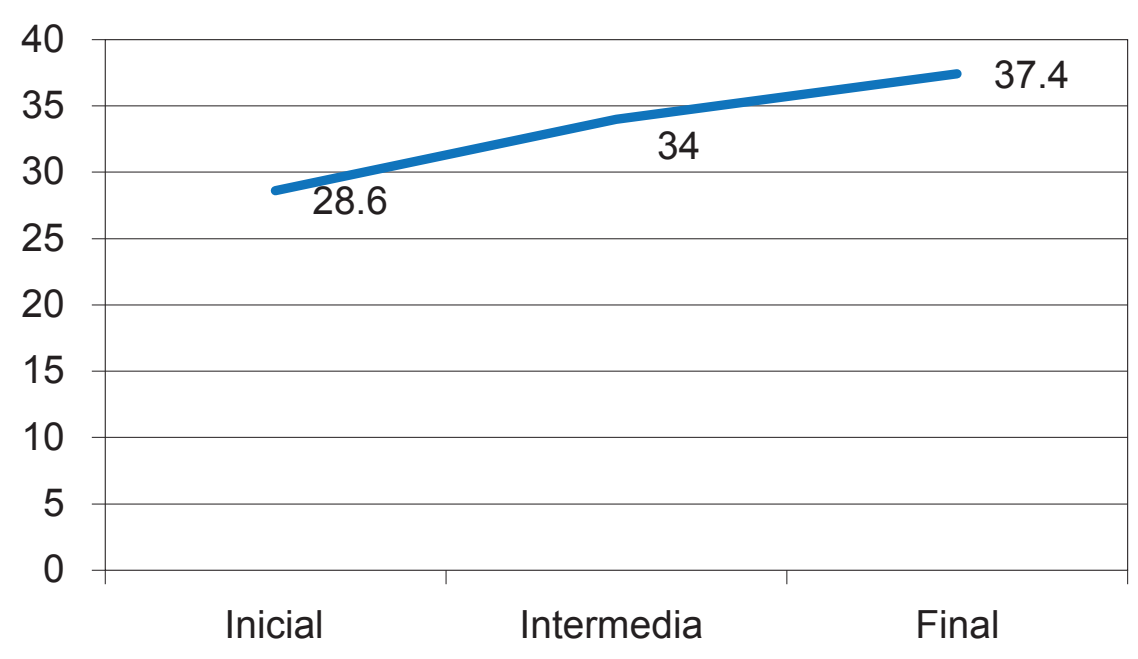

\subsubsection{Variables sociales}

Hay que diferenciar la incidencia de las variables en el entorno general y en el entorno más favorable a la elisión. De manera independiente, solo las variables sexo y edad presentan correlación con la elisión de la $d$ en el entorno general. Sin embargo, en el entorno -ado la elisión viene 
determinada por el nivel de estudios de los sujetos y, sobre todo, por la interrelación de los rasgos sociales.

Tabla 5. Variables sociales correlacionadas con la realización del segmento /d/ (entorno general)

\begin{tabular}{|c|c|c|c|c|c|}
\hline & \multirow[t]{2}{*}{ Variantes } & \multicolumn{2}{|c|}{ Elisión } & \multicolumn{2}{|c|}{ Total } \\
\hline & & $\mathbf{N}$ & $\%$ & $\mathbf{N}$ & $\%$ \\
\hline Sexo & Hombres & 431 & 55.3 & 2640 & 48.4 \\
\hline $\begin{array}{l}(\chi 2=92.999(2) ; \mathrm{p}=0.000 ; \\
\text { V de Cramer: } 0.131, \mathrm{p}=0.000)\end{array}$ & Mujeres & 349 & 44.7 & 2820 & 51.6 \\
\hline Edad & $1^{a}$ generación & 293 & 37.6 & 1913 & 35 \\
\hline$(\chi 2=93.812(4) ; p=0.000$ & $2^{a}$ generación & 198 & 25.4 & 1497 & 27.4 \\
\hline V de Cramer: 0.093, $\mathrm{p}=0.000$ ) & $3^{a}$ generación & 289 & 37.1 & 2050 & 37.5 \\
\hline Total & & 780 & 100 & 5460 & 100 \\
\hline
\end{tabular}

En el entorno general y en relación al sexo, la sociolingüística ha mostrado profusamente que en los procesos de variación donde alternan variantes con prestigio abierto y encubierto, los hombres se muestran más afines a las variantes con prestigio encubierto, mientras que las mujeres se decantan por las variantes con prestigio abierto (hipótesis 2). Así sucede en el barrio de Salamanca, donde los hombres eliden más (55.3\%) que las mujeres $(44.7 \%)$. En cuanto a la edad, la generación más joven es la que muestra una tendencia más clara a la elisión (37.6\%), seguida de la tercera generación (37.1\%). Frente a estas, los hablantes del grupo intermedio de edad se muestran más conservadores, con tasas de elisión inferiores (25.4\%) a las de jóvenes y mayores. Esta distribución del proceso por grupos de edad indica una involución de la relajación en el paso de la tercera 
a la segunda generación que vuelve a cobrar vitalidad en los más jóvenes, quienes retoman la elisión en niveles que superan a los de sus abuelos.

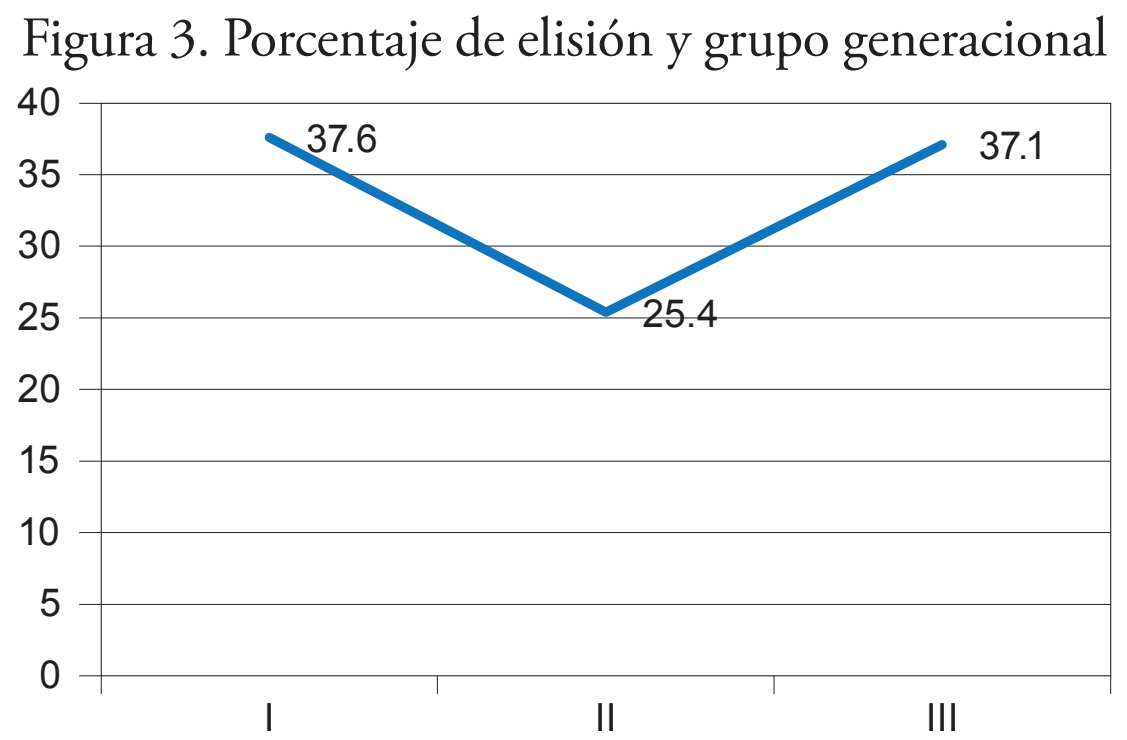

Tras el análisis de todas las variables en el entorno general, se procedió a un estudio de la incidencia de los factores sociales sobre la elisión en el entorno -ado con el fin de determinar qué hablantes favorecen el cambio en ese contexto específico. El nivel de estudios no determina la elisión en el entorno general, pero sí en el entorno -ado, donde son los universitarios quienes lideran la elisión, por delante de los hablantes con estudios primarios y secundarios.

La correlación entre la elisión, el sexo y la edad muestra en el comportamiento de hombres y mujeres un cambio de pauta generacional que se ilustra en la figura 4. La tercera generación es innovadora, la segunda es conservadora y la primera vuelve a ser innovadora. Esta curva en forma de "uve" corresponde al habla masculina, pues la de las mujeres sigue una secuencia distinta: los hombres de la tercera generación eran más innova- 
Tabla 6. Factores sociales correlacionados con la realización del segmento /d/ (entorno -ado)

\begin{tabular}{llcccr}
\hline & & \multicolumn{3}{c}{ Elisión } & \multicolumn{2}{c}{ Total } \\
& & N & \% & N & \multicolumn{1}{c}{$\%$} \\
\hline Nivel de estudios & Primarios & 165 & 33.5 & 275 & 30.5 \\
$\left(\chi^{2}=9.577(4) ; \mathrm{p}=0.048 ;\right.$ & Secundarios & 163 & 32.7 & 289 & 32 \\
V de Cramer: $0.073, \mathrm{p}=0.048)$ & Universitarios & 170 & 34.1 & 339 & 37.5 \\
Total & & 498 & 100 & 903 & 100 \\
\hline
\end{tabular}

dores que las mujeres de su edad pero en el paso de la segunda a la primera generación la sociedad retomó en el entorno - ado la pauta innovadora de los mayores bajo liderazgo femenino, pues las mujeres jóvenes superan el índice de elisión de los hombres de su edad. Este cambio de tendencia puede explicarse por el mayor acceso a la instrucción y a la vida laboral de las mujeres jóvenes.

Figura 4. Porcentaje de elisión, sexo y edad (entorno -ado)

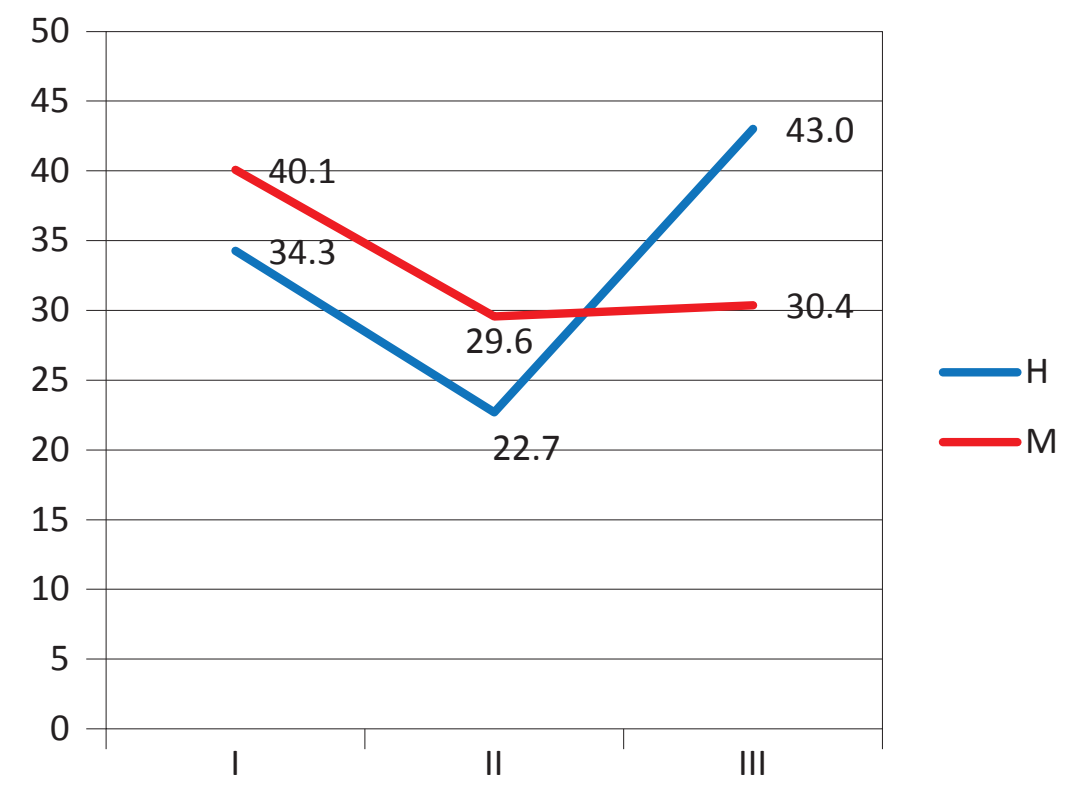


La combinación de la edad con el nivel de instrucción muestra la complejidad de patrones de comportamiento que pueden darse en una comunidad de habla y cómo se produce la interacción entre factores. Los hablantes de instrucción primaria adoptan un patrón lineal ascendente según el cual la elisión en -ado es menor entre los más jóvenes y aumenta en el resto de generaciones. Los hablantes de estudios secundarios presentan el patrón inverso: la elisión va decreciendo paulatinamente a medida que aumenta la edad de los sujetos. Por último, los universitarios muestran un patrón en "uve", según el cual la generación intermedia se sitúa por debajo de los sujetos de las generaciones de los extremos.

Figura 5. Porcentaje de elisión, edad y nivel de instrucción (entorno -ado)

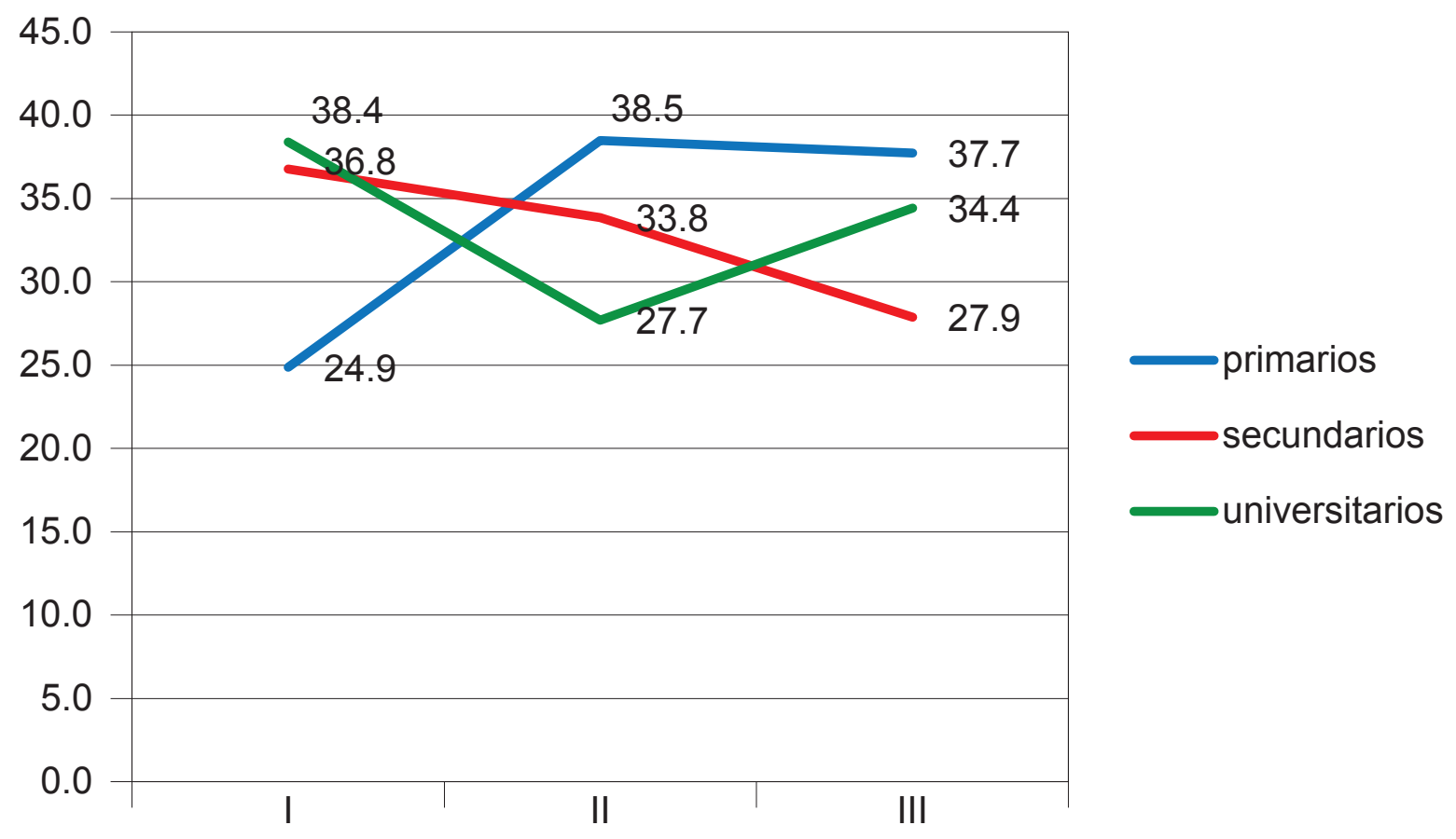


Pero aún podemos aproximarnos más y observar la interacción de los tres factores sociales considerados, que coincide con las casillas establecidas en la muestra. La correlación de esta nueva variable ha resultado significativa $\left({ }^{2}=123.519, \mathrm{p}=0.000 ; \mathrm{V}=0.262, \mathrm{p}=0.000\right)$ y será este análisis el que nos permita acotar con mayor precisión el perfil del hablante innovador en el entorno más favorable, a la vez que posibilita entender la complejidad de aspectos que operan en el proceso de cambio lingüístico.

Los datos aparecen representados en la figura 6, en la que podemos observar cómo la tercera generación sigue los patrones lineales esperables: la elisión va decreciendo a medida que aumenta el nivel de instrucción de los sujetos, tanto en el grupo masculino H-III como en el femenino M-III. Ese patrón regular, sin embargo, no tiene continuidad en el resto de grupos generacionales: los grupos M-I y H-II presentan patrones en "uve", en los que los sujetos del nivel educativo intermedio eliden menos que los más cultos; por el contrario, en el grupo masculino de primera generación H-I estos hablantes de estudios secundarios se sitúan a la cabeza de las soluciones elididas. El cambio más significativo, sin embargo, se produce en el grupo femenino de la generación intermedia M-II, donde la inversión de la tendencia respecto a la tercera generación es radical: las más instruidas y las de menor formación intercambian los papeles tradicionalmente asociados al factor educativo y mientras las universitarias adoptan decididamente los usos menos prestigiados, las mujeres de menor nivel educativo se inclinan hacia los usos ejemplares representados por la conservación de la dental. 
Figura 6. Elisión, sexo, edad y nivel de instrucción (entorno -ado)

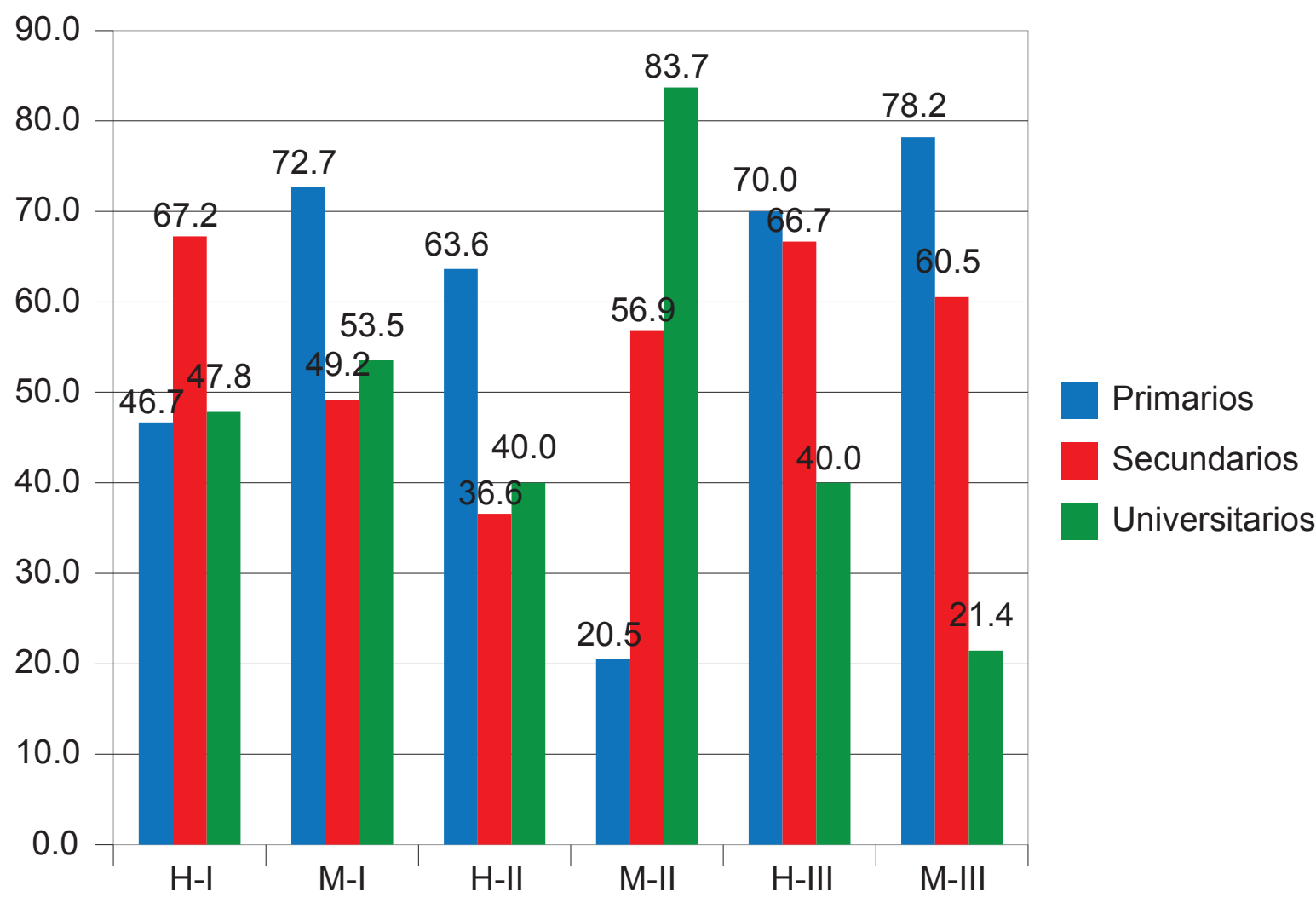

La explicación de este cambio de comportamiento habrá de buscarse en el contexto social en que se produce. La edad media de las mujeres encuestadas de la segunda generación es de 46.7 años, lo que quiere decir que nacieron en torno a 1955 y que se incorporaron a la vida laboral o accedieron a los estudios universitarios en los primeros años o mediados de la década de los 70. Este periodo es particularmente importante para la historia reciente de la sociedad espańola en lo que se refiere a la mujer, pues es cuando se producen cambios que afectan no solo a sus condiciones sociales sino también a los roles tradicionales 
que tenían asignados. Esta década es el periodo en el que se inicia de forma masiva la incorporación de la mujer al mundo laboral (Alonso y Furió 2007) y a los niveles educativos superiores, hasta el punto de que en 1975 el porcentaje femenino en la universidad representaba ya un tercio del alumnado y en carreras como Farmacia, Filosofía o Magisterio constituía el grupo mayoritario (Laorden y Giménez 1978; López de la Cruz 2001).

Estos cambios sociales tuvieron, como muestra el análisis, su correlato en el comportamiento lingüístico y podemos aventurar una explicación en el valor sintomático del lenguaje. Es sabido que la conservación representa la lengua ejemplar, el modelo lingüístico, y que se asocia con los estilos más formales y con la distancia social, mientras que la elisión es el modelo vernacular, asociado con la informalidad y la solidaridad. Las universitarias emplean la elisión como un modo de aproximar su comportamiento al del grupo masculino y a los esquemas de solidaridad y de poner de manifiesto que no son diferentes a los varones tampoco en lo lingüístico. Las mujeres de menor nivel de instrucción, por su parte, son conscientes de que un medio para favorecer la inserción sociolaboral consiste en mostrar no solo su capacidad profesional, sino también su dominio lingüístico y, como estrategia consciente o inconsciente, adoptan los modelos lingüísticos de los grupos sociales más altos. De este modo, mediante dos estrategias de orientación contraria ambos subgrupos invierten sus tendencias "naturales" para facilitar sus intereses como colectivo y lograr así el progreso económico y la plena integración social. 
2.2.4. Conclusiones sobre la incidencia de las variables independientes en la dental

1. En relación con el entorno general, se comprueba la hipótesis 1 sobre elisión de la dental: en el barrio de Salamanca de Madrid, la tendencia general es conservadora, pues en el contexto general la elisión apenas se produce en el 15\% de los casos. En la geografía peninsular, este dato sitúa a Valencia y a Madrid como conservadoras en relación con Granada y Málaga. El conservadurismo fónico en Madrid se habría agudizado a lo largo de la segunda mitad del siglo $\mathrm{xx}$, en convergencia con la mitad norte peninsular, limitando los contextos en que tradicionalmente podía elidirse la dental.

2. La elisión en el entorno general solo mantiene correlación con el sexo y la edad de los hablantes, como preveía la hipótesis 2 . La distribución de la elisión por grupos de edad indica una involución de la relajación en el paso de la tercera a la segunda generación que vuelve a cobrar vitalidad en los más jóvenes, quienes retoman la elisión en niveles que superan a los de sus abuelos. Los hombres se muestran más receptivos a la innovación que las mujeres.

3. La mayor incidencia de los factores lingüísticos frente a los socioestilísticos se ajusta a las previsiones de la hipótesis 3 .

4. La elisión de la dental en el caso madrileño se ajusta mejor al modelo del cambio fónico que al de difusión léxica (hipótesis 4), pero con diferencias de contextos y de frecuencia. La elisión aparece condicionada por restricciones de marcación, en el sentido de que se 
produce en contextos en los que la presencia del segmento no es imprescindible.

5. En cuanto al entorno restringido, se comprueba la hipótesis 5, pues en Madrid la elisión de la dental no es un cambio general, sino una innovación circunscrita casi exclusivamente al entorno -ado. El análisis de entornos restringidos deja ver que sí hay innovación en un conjunto limitado de contextos y de palabras, en determinadas situaciones discursivas y por parte de algunos hablantes concretos. Determinados factores y contextos lingüísticos favorecen exponencialmente la elisión: cuando el acento precede inmediatamente a la dental; cuando la dental es parte de un morfema flexivo; en palabras trisílabas; en el morfema -ado de participios y adjetivos; y todo y toda cuando forman parte de un sintagma con varios términos.

6. Se comprueba la hipótesis 6 para el entorno -ado: la variación de la dental en ese contexto es un cambio consciente que funciona como marcador en la comunidad. La correlación con variables estilísticas indica que el cambio es consciente; los hablantes eliden la dental cuando adoptan un tono informal, lo que explica que haya estilos discursivos que la favorezcan más y que, a medida que avanza la entrevista y el hablante se siente más relajado, aumenten sus elisiones. En el entorno más favorecedor de la elisión, las mujeres de la segunda generación presentan el comportamiento más diferenciado y son las promotoras de los cambios más significativos. No obstante, como las causas que motivan esos cambios son diferentes para cada uno de los subgrupos femeninos, el resultado final es una especie de equilibrio, una aparente neutralización de las tendencias. 


\subsection{Análisis de la variación individual}

El comportamiento lingüístico de los individuos está relacionado con sus características sociales, pero estas no son por sí solas suficientemente explicativas. En gran medida, es la decisión del sujeto como ser individual la que le lleva a seleccionar variantes, a preferir usos y, en definitiva, a adoptar decisiones lingüísticas que le permiten influir en otros individuos a través de sus redes sociales. Por ello, es importante conocer en más detalle quiénes son los sujetos que componen la muestra y analizar su comportamiento ante el fenómeno que estamos analizando.

La sociolingüística actual tiene gran interés en determinar el papel que desempeña el individuo en los procesos de cambio, dado que la innovación se produce siempre en la interacción cara a cara, y en este sentido, se interesa por determinar qué individuos actúan en la comunidad como los promotores de los cambios lingüísticos. Los sujetos que se encuentran a la cabeza de estos cambios se denominan líderes lingüísticos y entre los diversos tipos que podemos encontrar interesa ahora distinguir los líderes del cambio y los líderes de la variación (Martín Butragueño 2014:580). Los líderes del cambio son la avanzadilla del proceso del cambio, mientras que los líderes de la variación son quienes más promueven las variantes consideradas normativas en una comunidad de habla. Veamos primero en qué medida los madrileños del distrito de Salamanca eliden la dental en el entorno general y después en el entorno -ado. 


\subsubsection{Entorno general}

La figura $7^{12}$ representa el porcentaje individual de elisión de los hablantes en el entorno general y pone de relieve cómo, por encima de cualquier otra circunstancia, es la actitud individual hacia la variable lingüística la que mejor explica la variación. Los usos individuales reflejados en la figura presentan una notable oscilación que encuentra su límite inferior en los

Figura 7. Porcentaje individual de la elisión de d/ (entorno general).

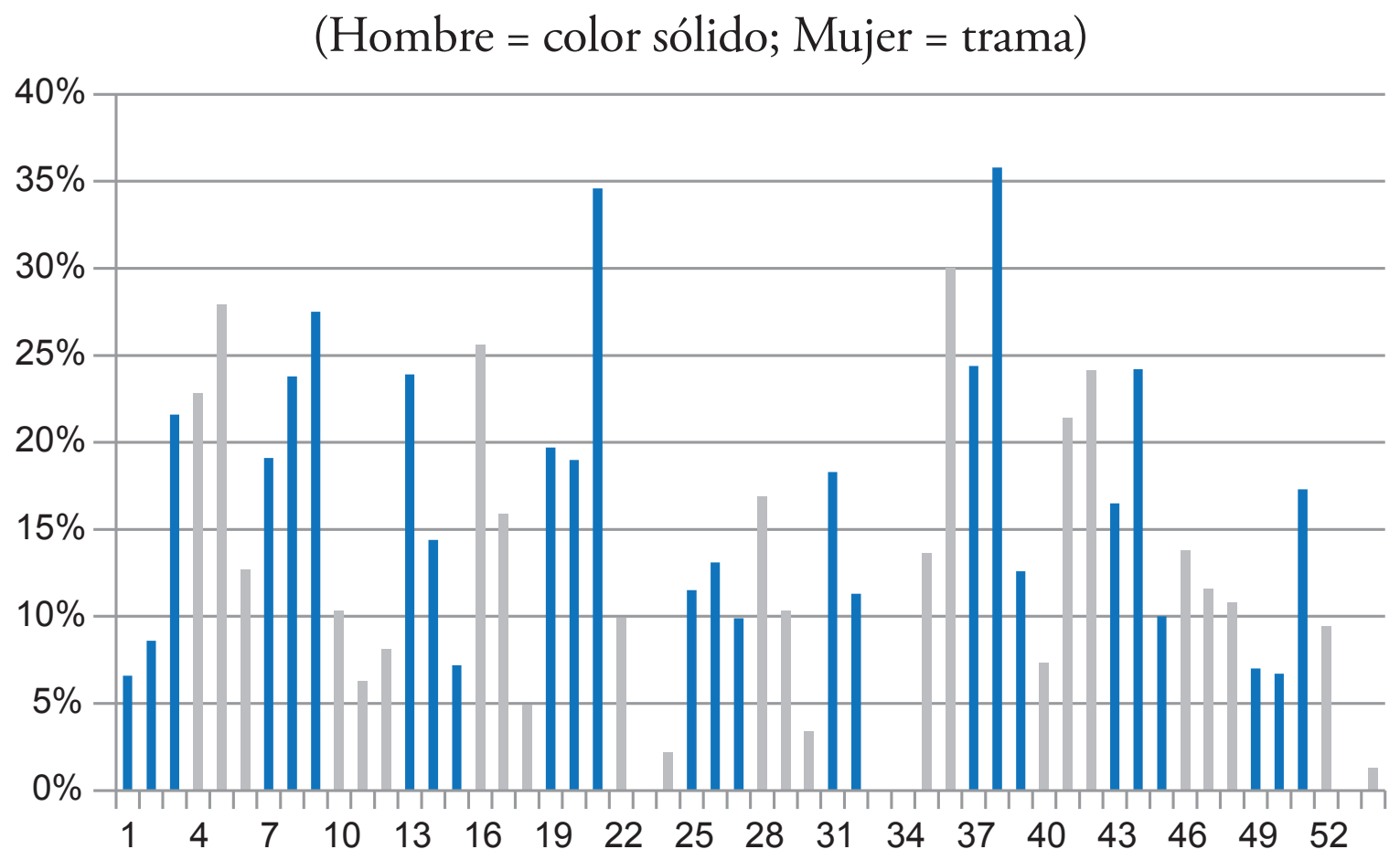

12 En estas figuras y en las que siguen se presentan los 54 informantes ordenados del siguiente modo: el primer tercio ( $=18$ sujetos) corresponde al nivel de instrucción alto, el segundo al nivel de instrucción media y el tercero al nivel de instrucción baja. Dentro de cada tercio, los 6 primeros son de la primera generación (3 hombres y 3 mujeres), los 6 siguientes de la segunda y los 6 últimos de la tercera. 
que nunca elidieron la dental en las encuestas y su límite superior en aquellos para quienes la elisión es bastante habitual, con porcentajes iguales o superiores al $25 \%$, esto es, en una de cada cuatro ocasiones. Los primeros podrían considerarse líderes lingüísticos de la resistencia al cambio lingüístico, mientras que los segundos son quienes más decididamente lo promueven en la comunidad madrileńa.

Tomando como punto 0 la media porcentual de la elisión individual -que se sitúa en el $14.7 \%$-, se puede distribuir a los sujetos según su desviación respecto a ese estadístico. Esto es lo que nos ofrece la figura 8 , donde se aprecia que la variación no se distribuye simétricamente: por una parte, la diferencia porcentual en la zona de valores positivos presenta un rango mayor que la de la zona negativa, lo cual indica que los hablantes innovadores tienen un comportamiento menos homogéneo que los conservadores. Por otra parte, tampoco hay simetría en el número de sujetos que se sitúa en cada polo: en el área de los valores negativos hay 31 sujetos (el $56.4 \%$ del total), de los cuales 19 son mujeres y 12 hombres, mientras que en la zona de los valores positivos (los que favorecen la elisión), el número de sujetos es de solo 23 (43.6\%), 15 hombres y 8 mujeres. Por último, una tercera asimetría se produce entre el tercio izquierdo de la figura, donde se sitúan los informantes más jóvenes, y el resto, donde se ubican los de la segunda y la tercera generación. También aquí se constata que los innovadores se encuentran más entre los jóvenes que en las otras dos generaciones.

Para distinguir cuáles son los hablantes más destacados en el comportamiento innovador y en el conservador, se ha tomado como referencia el valor de la desviación típica (8.99). La figura 8 refleja la desviación indivi- 
Figura 8. Diferencia de cada sujeto respecto a la media de elisión

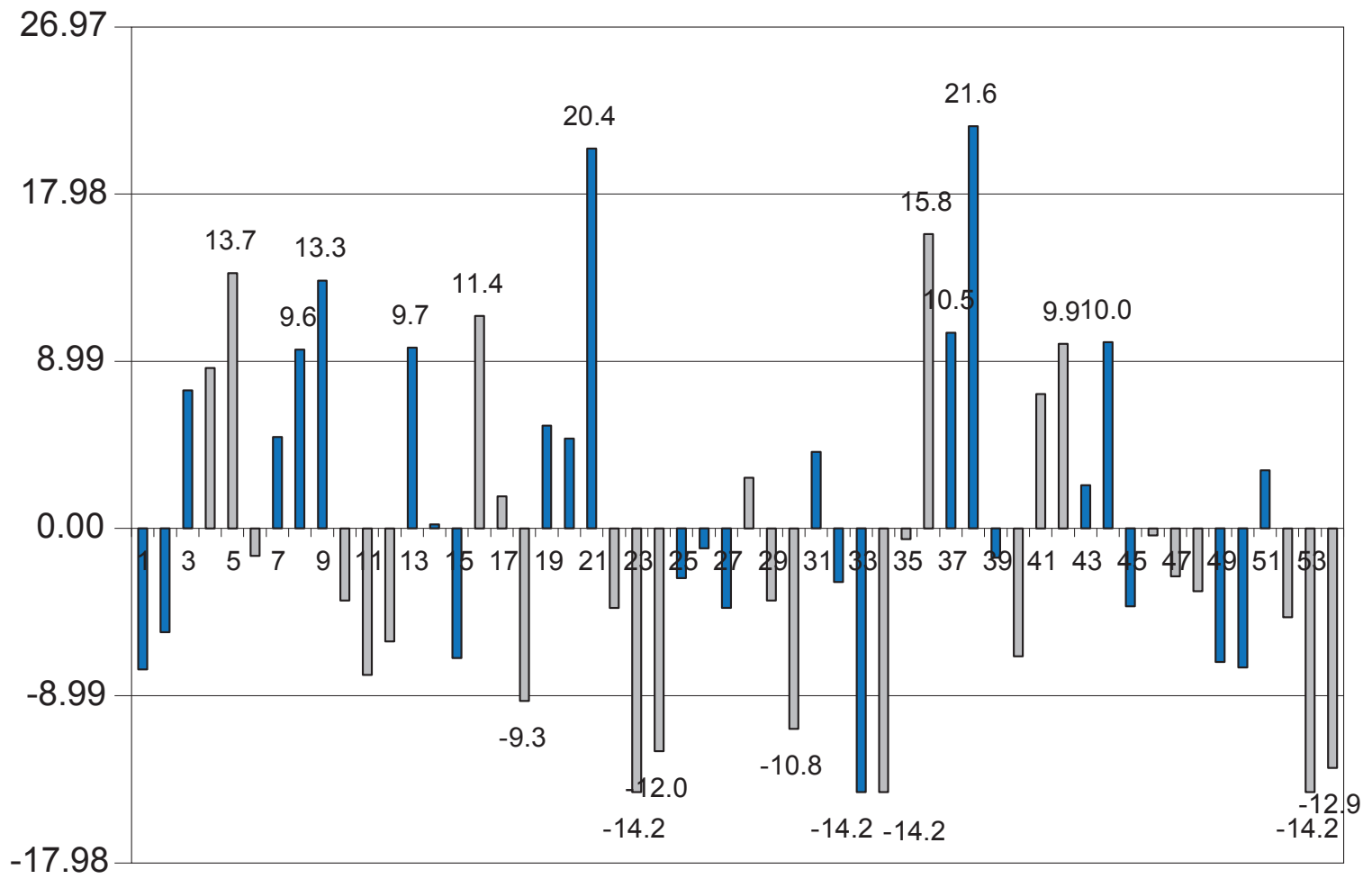

dual de los sujetos que superan esa frontera. Se inclina hacia la elisión un grupo de once personas, los informantes 5, 8, 9, 13, 16, 21, 36, 37, 38, 42 y 44 , a quienes podemos considerar líderes del cambio por ser quienes más promueven la variante innovadora. En este grupo predominan los hombres $(7 \mathrm{H} / 4 \mathrm{M})$, los hablantes de instrucción primaria $(5 \mathrm{P} / 3 \mathrm{~S} / 3 \mathrm{U})$ y los de la generación más joven (5 I/2 II/4 III); en cuanto a la clase social, abundan los de clase media (1 CB/1 CMB/7 CM/1 CMA). Las profesiones $\mathrm{u}$ oficios que desempeñan estas personas son heterogéneas, pero predominan las que no requieren especial dominio de los registros formales: 
hay tres estudiantes, dos amas de casa, dos jubilados, un administrativo, un repostero, un maestro platero y un técnico de cajeros automáticos.

Todavía dentro de este grupo de líderes del cambio, hay que destacar algunos sujetos que duplican la diferencia respecto a la desviación típica: el informante 38 es quien muestra un comportamiento lingüístico más avanzado: es un maestro platero de clase media y 79 años de edad en el momento de la encuesta, que había cursado estudios primarios; su cónyuge es de Madrid y sus ascendientes proceden de regiones del norte de Espańa, la madre de Burgos y el padre de Asturias. El informante 21 es un hombre de clase media-baja de 41 años, repostero de profesión, que no llegó a completar los estudios básicos y cuyos padres son gaditano y madrileña respectivamente. A este reducido grupo podrían añadirse los informantes que superan la desviación típica y media, zona en la que se encuentran otros dos sujetos: la informante 36, una ama de casa de 40 ańos licenciada en Derecho, de clase media-alta, de padre vallisoletano y madre donostiarra y casada con un madrileño, y la informante número 5, una estudiante soltera de clase media que trabaja en la tienda de sus padres, ambos madrileños.

Este subconjunto del grupo de los innovadores constituye la avanzadilla de la innovación lingüística en el entorno general. Conforman el perfil individualizado de los hablantes que tienden a elidir en todos los contextos. Hay que destacar el hecho de que dos de los cuatro tengan ascendentes originarios de las regiones vasca o cántabra -áreas en la que el proceso de elisión en el entorno -ado se encuentra más avanzado (cf. Etxebarria 2007; Ońederra 2007) y que otro de ellos tenga ascendientes gaditanos, de una zona en la que la elisión se encuentra en un estadio más avanzado. Estos 
hechos vendrían a avalar la hipótesis de que el cambio que está ocurriendo en la ciudad de Madrid supone una intersección entre la tendencia general innovadora de la hablas meridionales y la elisión restringida al entorno -ado, de las hablas castellanas de la cornisa cantábrica.

De forma complementaria, el análisis de la variación debe considerar el comportamiento individual de los que se resisten a la innovación y siguen las pautas normativas, pues es el contraste entre la tendencia innovadora y la conservadora lo que permitirá plantear hipótesis sobre la dirección del cambio lingüístico. En la zona de los valores negativos, donde se sitúan los hablantes líderes de la variación, hay un grupo formado por siete sujetos. De ellos, los informantes 23, 33, 34 y 53 nunca elidieron la dental en las encuestas, mientras que los sujetos 54, 24, 30 y 18 presentan índices de elisión por debajo del 5\%. Hay algunas características comunes en este grupo, en el que predominan claramente las mujeres (6 $\mathrm{M} / 1 \mathrm{H})$, la generación intermedia (0 I/5 II/ 2 III) y los de instrucción alta $(2 \mathrm{P} / 1 \mathrm{M} / 4 \mathrm{U})$; ninguno de ellos pertenece a las clases bajas (0 CB/0 $\mathrm{CMB} / 5 \mathrm{CM} / 2 \mathrm{CMA}$ ). En cuanto a las profesiones ejercidas por esas personas, encontramos dos amas de casa, un administrativo, un médico, una profesora de secundaria, una farmacéutica jubilada y una bióloga, también jubilada. Predominan, pues, aquellas profesiones que requieren dominio del registro formal para el desempeño de su actividad diaria (profesor, médico, farmacéutica), aunque no parece ser este un elemento concluyente. Por último, en cuanto a la ascendencia de los padres o del cónyuge, predominan los hablantes de ascendencia meridional frente a los de Madrid o de ascendencia mixta; curiosamente, no hay ninguno que proceda del norte. 
Por otra parte, para conocer la actitud de los individuos hacia la elisión interesa observar su comportamiento en los diferentes contextos de la dental. Los datos se reflejan en la figura 9, que presenta a los informantes ordenados según la frecuencia de elisión en el entorno más favorable y su comportamiento en los distintos contornos. Se observa cómo el entorno - ado es el que muestra para cada sujeto un porcentaje de elisión más alto. Solo en dos casos la elisión en este entorno presenta porcentajes inferiores: se trata de los sujetos 48 y 32, que eliden más en la terminación -odo; en otros cuatro casos la elisión en -ado coincide con la de otros entornos, como vemos en los informantes 24, 50, 44 y 27.

Figura 9. Porcentaje individual de elisión según los contornos fónicos (los números en el eje de abscisas corresponden a cada informante)

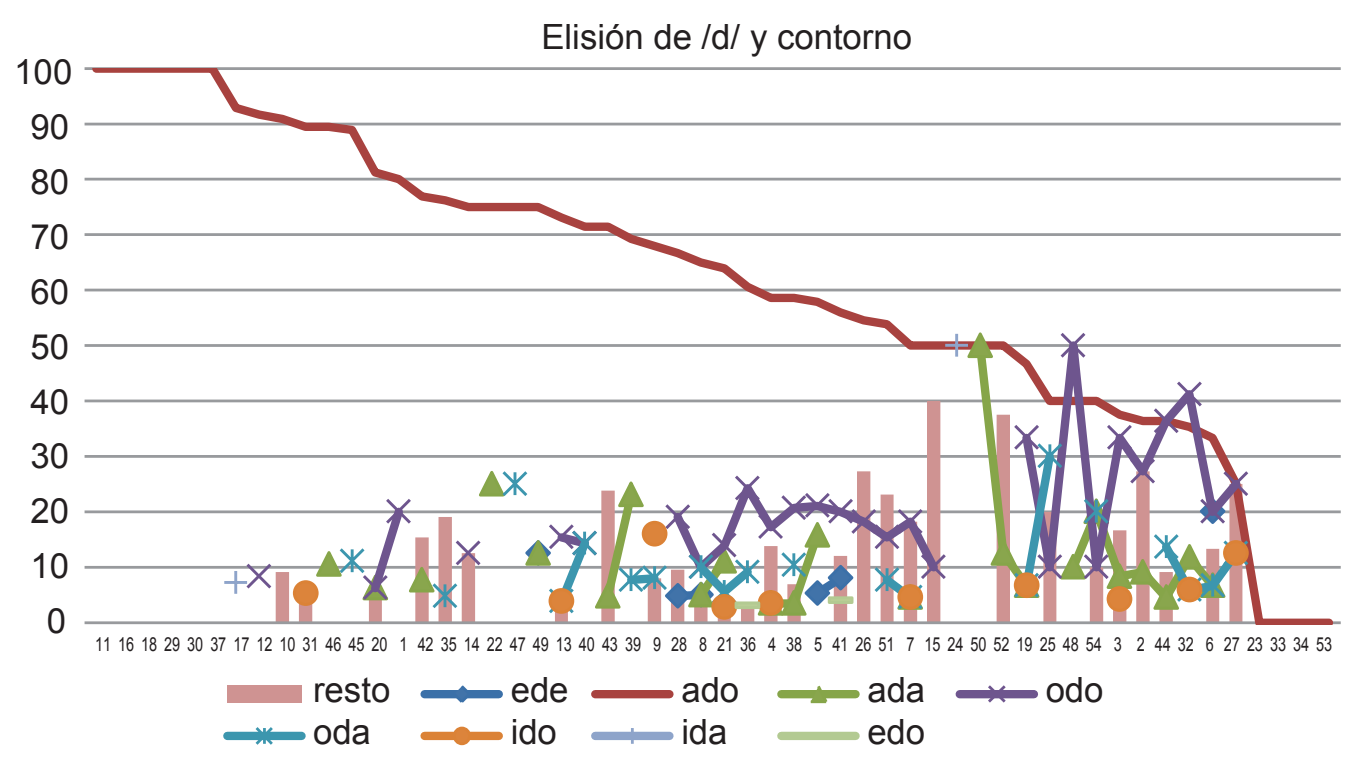

Hay una serie de sujetos, situados en la zona izquierda de la figura, que eliden exclusivamente en la terminación -ado: se trata del grupo formado 
por las mujeres $11,16,18,29,30 \mathrm{y}$, como único hombre, el 37. Otro aspecto destacable es que muchos sujetos restringen la elisión a uno o dos contornos y conservan siempre la dental en el resto: así, los informantes 17 y 24 solo eliden en las terminaciones -ado e -ida; los informantes 12 y 1 suprimen la dental solo en -ado y -odo; los informantes 46, 22 y 50 limitan su elisión a -ado y -ada y los infs. 45 y 47 lo hacen únicamente en -ada y -oda. Estos comportamientos son una muestra más de las restricciones que los hablantes madrileños se imponen a sí mismos a la hora de seleccionar los contextos de elisión.

En la zona de la derecha de la figura -exceptuados los cuatro que mantuvieron siempre el fonema- se ubican los sujetos que menos restricciones se imponen en relación con los contornos de elisión. Hay que destacar que no hay ningún hablante que elida en los ocho contornos considerados: el máximo de contornos para un mismo hablante es de seis, comportamiento que muestran los sujetos 4, 6, 7, 8 y 21. En estos hablantes, la elisión en -ado no alcanza valores superiores a la elisión del resto de los contextos, de donde se deduce que desde este grupo no se lidera ni favorece el cambio en el entorno restringido. La adscripción de casi todos estos sujetos al primer grupo generacional y a los niveles de instrucción bajo o medio nos estaría dando una clave sobre la posible evolución de la elisión en la comunidad madrileńa.

Por último, quienes reparten la elisión de manera más equilibrada son los sujetos 27, 6, 32, 44, 2, 3, 54, 25 y 48, que presentan frecuencias en -ado por debajo del $40 \%$ y relativamente altas en los demás contextos. En este grupo hay un claro predominio de los hombres $(6 \mathrm{H} / 3 \mathrm{M})$ y de la clase media ( $1 \mathrm{CB} / 1 \mathrm{CMB} / 7 \mathrm{CM})$, mientras que el reparto por edades y por nivel educativo está equilibrado. 


\subsubsection{Entorno -ado}

A continuación se analiza el comportamiento de los madrileños del distrito de Salamanca respecto a la elisión en el entorno más favorecedor, la terminación -ado, donde la elisión supera el 55\%.

Figura 10. Porcentaje individual de la elisión de d/ (entorno -ado).

$($ Hombre $=$ color sólido; Mujer $=$ trama $)$

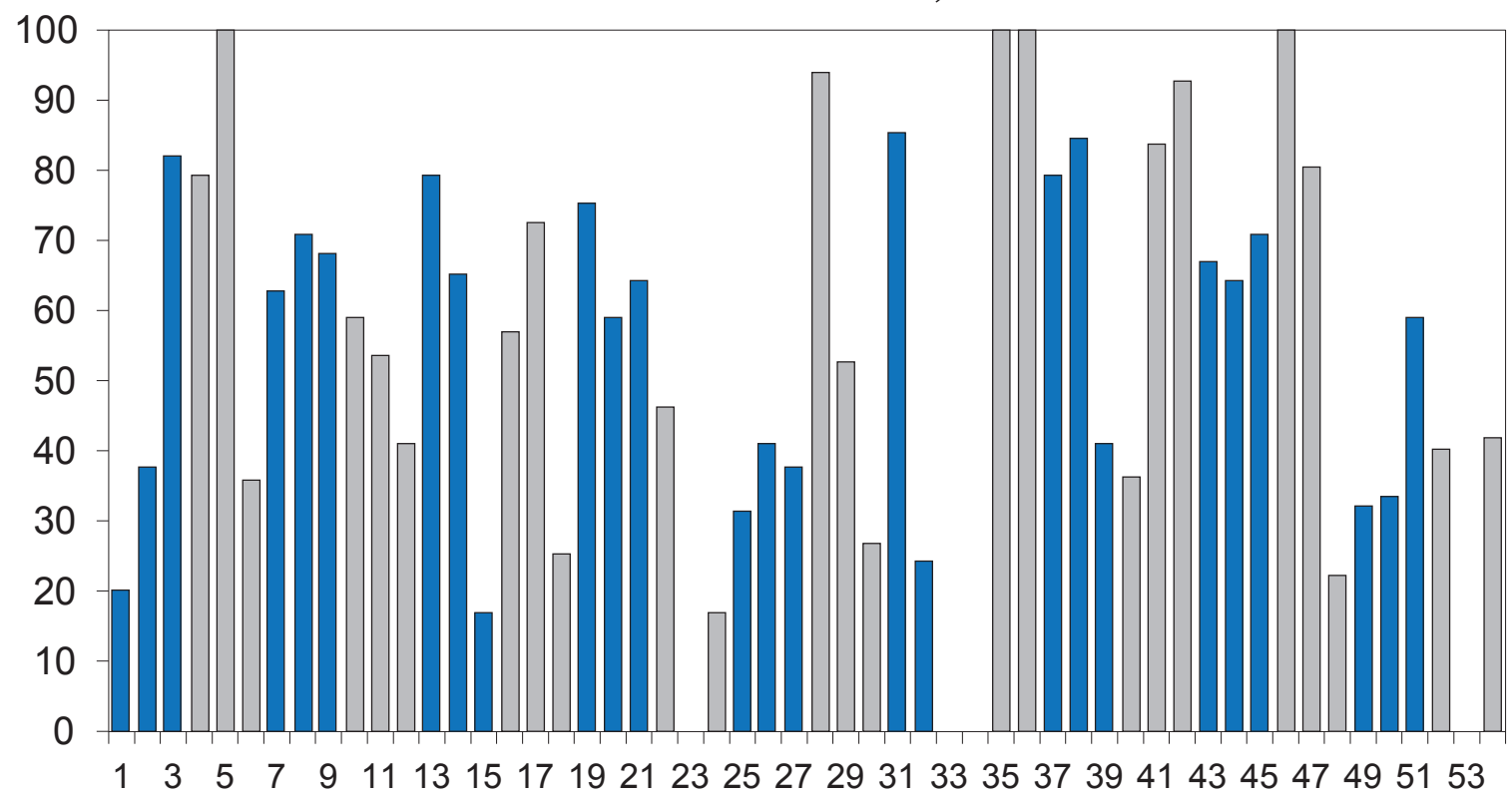

El comportamiento individual de los madrileños en el entorno más favorecedor de la elisión presenta un panorama de patrones individuales muy diferentes al que aparecía en el entorno general (figura 10). ${ }^{13} \mathrm{La}$

13 No son contradictorios los datos relativos a -ado que aparecen en esta figura con los de la figura 9. En aquel se representan los contornos fónicos en los que cada hablante elide; en la figura 10 se señala el porcentaje individual de elisión en -ado. De hecho, un hablante puede eliminar la $d$ solo en -ado independientemente de que unas veces lo haga y otras no, y, del 
oscilación, en este caso, abarca todo el espectro: desde el 0\%, correspondiente a los informantes que nunca elidieron la dental, hasta el 100\% de los cuatro que la elidieron en todas las ocasiones (informantes 5, 35, 36 y 46). Además, hay que destacar que treinta encuestados (55\% del total) eliden la dental en más de la mitad de las ocasiones en que aparece en este entorno y 15 (28\%) la omiten al menos dos de cada tres veces. Esa misma figura 10 aporta también información sobre el comportamiento de los sujetos según el sexo. Las mujeres madrileñas son las que obtienen porcentajes de elisión más altos, hasta el punto de que las cuatro personas que eliden siempre son todas mujeres. La adopción de este comportamiento por parte del grupo femenino estaría indicando que la elisión en este entorno es un rasgo propio de la comunidad y valorado positivamente. ${ }^{14}$

Siguiendo la pauta establecida en el apartado anterior, procedemos ahora a distribuir a los madrileños encuestados en relación con su diferencia respecto a la media de elisión, que es del 53.6\%. La figura 11 muestra una distribución bastante más equilibrada que la que veíamos en el entorno general: 28 sujetos $(16 \mathrm{H} / 12 \mathrm{M}$ ) eliden más de la media y 26 menos (11 H/15 M). En el grupo de quienes favorecen la elisión, la proporción es favorable a los hombres $(16 \mathrm{H} / 12 \mathrm{M})$. Parecida simetría encontramos en

mismo modo, un hablante puede eliminar la $d$ siempre en -ado además de en otros contextos.

14 Estos datos avalan muchas de las características particulares de los líderes lingüísticos, quienes, según Labov (2001:360), poseen los siguientes rasgos: a) suelen ser mujeres; b) se concentran en el centro de los grupos jerárquicamente dominantes en la sociedad; c) tienen contactos estrechos dentro de sus redes sociales; d) no se limitan a mantener contactos con sus redes más próximas; y e) establecen contactos con individuos de diferente estatus, por encima o por debajo en la escala social. 
el rango de la variación porcentual (46.4 los que más eliden, $-53.6 \%$ los que menos), lo que significa que el comportamiento de los madrileños es más homogéneo en este entorno -ado que en el general.

Figura 11. Diferencia de cada sujeto respecto a la media de elisión $($ entorno $-a d o)($ Hombre $=$ color sólido; Mujer = trama $)$

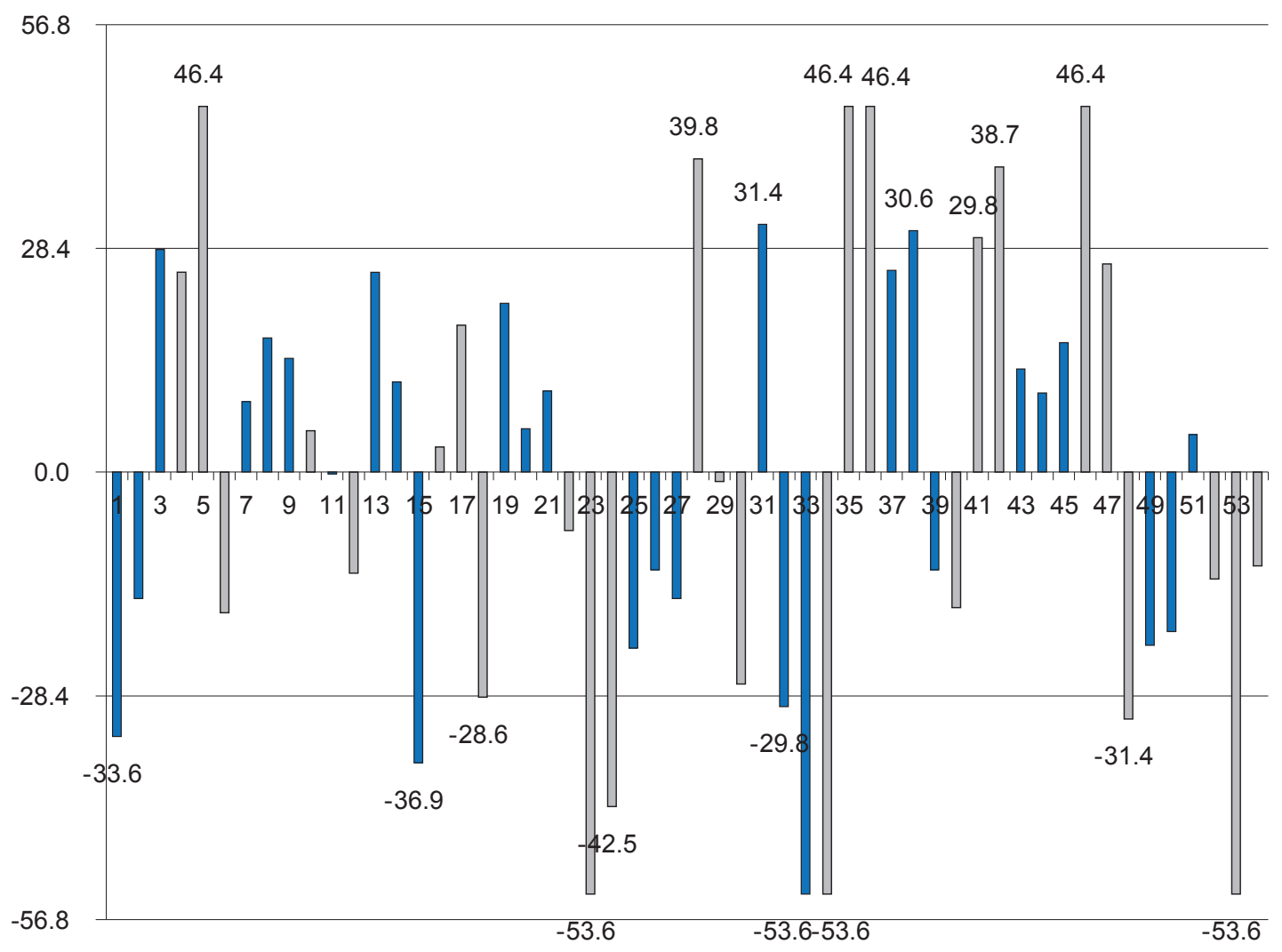

El estadístico correspondiente a la desviación típica es 28.4, y también aquí nos vamos a valer de él para determinar quiénes son los líderes del cambio lingüístico y quiénes los más reacios a la innovación. En el grupo de los más innovadores (sujetos 5, 28, 31, 35, 36, 38, 41, 42 y 46) predominan las mujeres (2H/7M) y los mayores de 35 años (1 I/4 II/4 III), 
mientras que no destaca ningún nivel instrucción (4 P/2 S/3 U). En relación con las profesiones, sobresalen las amas de casa (cinco mujeres), aunque también hay un abogado, un documentalista, un estudiante y un maestro platero. Respecto al origen de sus ascendentes, en tres casos los padres procedían de la ciudad de Madrid y cuatro tenían el padre o la madre de San Sebastián o de Burgos.

Todavía podemos detenernos un poco más en el análisis de la figura 11 para fijar la atención en los cuatro sujetos que elidieron siempre que la palabra terminaba en -ado. Estos son, sin duda, los máximos promotores de la innovación lingüística, por lo que interesa especialmente conocer sus características. Todos ellos presentan una desviación respecto a la media de 46.4 puntos porcentuales y son los informantes 5, 35, 36 y 46. Un rasgo que los une tiene que ver con su raigambre madrileña: de tres de ellos tanto los padres como el cónyuge -en caso de tenerlo- eran originarios de Madrid, ${ }^{15}$ lo que avala la hipótesis de que el cambio está siendo especialmente promovido por los oriundos madrileńos, quizá por considerarlo rasgo idiosincrásico de la ciudad.

En conclusión, el comportamiento de los madrileños del barrio de Salamanca hacia la elisión está en gran medida determinado por los rasgos individuales de cada sujeto y su carácter más o menos renuente a la innovación lingüística. En relación con el entorno general, podemos decir que los madrileńos del barrio de Salamanca tienen una actitud desfavorable hacia la elisión, que se manifiesta en que los índices individuales suelen

15 El otro miembro de este grupo es la mujer catalogada con el número 38, cuyo cónyuge es también originario de Madrid. 
estar por debajo del $14 \%$. Hay madrileños que nunca eliden la dental y la mayor parte de los hablantes limitan los contornos en los que aceptan la elisión. Por otra parte, el perfil de los líderes lingüísticos del cambio en el entorno general es el de un varón joven sin estudios que ejerce una profesión para la que no se requiere dominio de los registros formales.

Respecto al entorno -ado, los patrones se invierten, pues a) los índices de elisión superan en muchos casos el $50 \%$, b) hay sujetos que eliden siempre la dental en este entorno, y c) otros hablantes solo eliden en este entorno. Los líderes lingüísticos del cambio en este entorno son mujeres mayores de 35 años y cuya familia es de origen madrileño. Estos hechos avalan la hipótesis de que el cambio se valora positivamente y se ha convertido en un marcador lingüístico de la comunidad de habla. Por último, a pesar de que contamos con pocos datos relacionados con el origen geográfico de los hablantes, parece constatarse que quienes promueven más decididamente el cambio en Madrid son aquellos que tienen vinculaciones por orígenes o por viajes y estancias con las áreas septentrionales de España en las que más adelantada va la elisión de $d$ en -ado.

\subsection{Análisis multivariante: la incidencia conjunta de los factores}

Hasta aquí se ha visto la incidencia que sobre la elisión de la dental ejerce cada una de las variables tomadas individualmente. Sin embargo, en la realidad estas variables actúan conjuntamente, de manera que la presencia de unas eventualmente puede incidir sobre el resto. Se hace necesario, por ello, buscar un modelo explicativo más ajustado recurriendo a técnicas estadísticas que permitan combinar y tratar conjuntamente las variables. 
2.4.1. Análisis de regresión (entorno general)

Es necesario recurrir a un análisis de regresión logística para poder ver en qué medida contribuyen solidariamente las variables seleccionadas a explicar la variación observada y determinar la importancia que cada variable individualmente tiene en la elisión de la $d$ intervocálica cuando interactúan conjuntamente, así como el peso de cada variante en la elisión. Para este propósito se ha utilizado el programa Goldvarb X, y la tabla 7 presenta la información resultante del análisis escalonado.

Tabla 7. Jerarquía de variables en la elisión de /d/ (Entorno general)

\begin{tabular}{llrrrr}
\hline Rango y variable & \multicolumn{1}{c}{ Variantes } & \multicolumn{1}{c}{ N } & \multicolumn{1}{c}{$\boldsymbol{f}$} & $\boldsymbol{P}_{\boldsymbol{1} \text { nivel }}$ & $\boldsymbol{P}_{\text {escal. }}$ \\
\hline 1. Contorno vocálico & $-a d o$ & 513 & 50.9 & 0.922 & 0.895 \\
Raz. ver. =-1647.236 P =0.000 & $-e d e$ & 10 & 6.2 & 0.430 & 0.809 \\
& - -do & 101 & 13.0 & 0.630 & 0.653 \\
& - oda & 33 & 17.8 & 0.712 & 0.565 \\
& $-e d o$ & 2 & 2.2 & 0.202 & 0.573 \\
& resto & 68 & 4.8 & 0.365 & 0.488 \\
& $-a d a$ & 38 & 4.7 & 0.360 & 0.270 \\
& $-i d o$ & 13 & 2.0 & 0.187 & 0.098 \\
2. Categoría gramatical & $-i d a$ & 2 & 7.0 & 0.078 & 0.092 \\
Raz. ver. =-1502.080 P = 0.000 & Interj & 14 & 46.7 & 0.890 & 0.982 \\
& Adv & 55 & 19.3 & 0.688 & 0.778 \\
& Det & 77 & 23.51 & 0.739 & 0.769 \\
& Part & 396 & 33.1 & 0.820 & 0.679 \\
& A & 117 & 15.9 & 0.636 & 0.632 \\
& Pro & 44 & 5.1 & 0.332 & 0.504 \\
& N & 65 & 4.9 & 0.324 & 0.475 \\
& V & 12 & 1.7 & 0.138 & 0.052 \\
\hline
\end{tabular}




\begin{tabular}{|c|c|c|c|c|c|}
\hline Rango y variable & Variantes & $\mathbf{N}$ & $f$ & $P_{1 \text { nivel }}$ & $P_{\text {escal. }}$ \\
\hline 3. Difusión léxica & además & 35 & 30.7 & 0.739 & 0.919 \\
\hline \multirow[t]{7}{*}{ Raz. ver. $=-1470.630 P=0.000$} & todavía & 4 & 19.0 & 0.601 & 0.844 \\
\hline & quedar & 13 & 7.4 & 0.340 & 0.852 \\
\hline & poder & 12 & 3.6 & 0.194 & 0.818 \\
\hline & nada & 22 & 5.3 & 0.266 & 0.589 \\
\hline & todo (mod.) & 93 & 23.4 & 0.344 & 0.561 \\
\hline & resto & 561 & 17.3 & 0.573 & 0.417 \\
\hline & todo (núc.) & 40 & 7.6 & 0.661 & 0.369 \\
\hline 4. Límite morfemático & $d$ morfemática & 530 & 24.4 & 0.694 & 0.700 \\
\hline Raz. ver. $=-1459.723 \mathrm{P}=0.000$ & d lexemática & 250 & 7.6 & 0.368 & 0.363 \\
\hline 5. Fase de la interacción & Final & 292 & 16.7 & 0.548 & 0.583 \\
\hline \multirow[t]{2}{*}{ Raz. ver. $=-1451.010 \mathrm{P}=0.000$} & Intermedia & 265 & 14.3 & 0.503 & 0.495 \\
\hline & Inicial & 223 & 12.0 & 0.452 & 0.463 \\
\hline 6. Planificación del discurso & Entrevista & 306 & 16.0 & 0.536 & 0.600 \\
\hline \multirow[t]{2}{*}{ Raz. ver. $=-1439.786 \mathrm{P}=0.000$} & Coloquio & 259 & 12.1 & 0.455 & 0.463 \\
\hline & Resto & 215 & 15.2 & 0.520 & 0.420 \\
\hline 7. Grado de especialización & Resto & 2 & 16.7 & 0.548 & 0.708 \\
\hline \multirow[t]{3}{*}{ Raz. ver. $=-1429.807 \mathrm{P}=0.000$} & Técnico & 159 & 19.1 & 0.590 & 0.661 \\
\hline & No técnico & 615 & 13.5 & 0.487 & 0.472 \\
\hline & Metalingüístico & 4 & 5.8 & 0.272 & 0.335 \\
\hline 8. Posición del acento & Precede & 729 & 17.1 & 0.618 & 0.578 \\
\hline \multirow[t]{2}{*}{ Raz. ver. $=-1421.463 \mathrm{P}=0.000$} & Sigue & 41 & 12.7 & 0.533 & 0.380 \\
\hline & Sílaba tónica & 10 & 1.1 & 0.084 & 0.205 \\
\hline 9. Tenor y proximidad & Desconocidos & 747 & 14.5 & 0.506 & 0.512 \\
\hline \multirow[t]{2}{*}{ Raz. ver. $=-1415.503 \mathrm{P}=0.005$} & Amigos & 21 & 11.5 & 0.438 & 0.339 \\
\hline & Conocidos & 12 & 8.8 & 0.367 & 0.278 \\
\hline 10. Tipo de discurso & Diálogo & 149 & 14.8 & 0.510 & 0.593 \\
\hline \multirow[t]{5}{*}{ Raz. ver. $=-1406.697 \mathrm{P}=0.006$} & Descriptivo & 42 & 15.3 & 0.521 & 0.586 \\
\hline & Narrativo & 196 & 14.2 & 0.497 & 0.498 \\
\hline & Argumentativo & 37 & 13.3 & 0.479 & 0.474 \\
\hline & Explicativo & 355 & 14.4 & 0.498 & 0.458 \\
\hline & Otros & 1 & 9.1 & 0.376 & 0207 \\
\hline
\end{tabular}


Sociolingüística DE LA Elisión De LA DeNTAL -/d/-

\begin{tabular}{llllll}
\hline Rango y variable & Variantes & N & \multicolumn{1}{c}{$\boldsymbol{f}$} & $\boldsymbol{P}_{\text {1 nivel }}$ & $\boldsymbol{P}_{\text {escal. }}$ \\
\hline 11. Número de sílabas & Bisílaba & 216 & 9.4 & 0.608 & 0.602 \\
Raz. ver. =-1401.549 P =0.008 & Trisílaba & 364 & 19.7 & 0.395 & 0.433 \\
& Polisílaba & 200 & 15.3 & 0.533 & 0.414 \\
12. Edad & 3a generación & 289 & 14.1 & 0.497 & 0.537 \\
Raz. ver. =-1398.070 P = 0.034 & 1a generación & 293 & 15.3 & 0.520 & 0.496 \\
& 2a generación & 198 & 13.2 & 0.479 & 0.354 \\
\hline
\end{tabular}

En coherencia con los análisis bivariantes, el modelo de regresión escalonada vuelve a mostrar que los factores lingüísticos son los que más importancia tienen en la elisión de la aproximante intervocálica: han sido seleccionadas seis variables lingüísticas y cuatro de ellas ocupan las primeras posiciones; en segundo lugar inciden algunas variables estilísticas, especialmente la fase de la interacción y el grado de planificación y especialización del discurso; por último, queda descartada la influencia de todas las variables sociales, con excepción de la edad.

El contorno vocálico que rodea la $d$ se ha mostrado como la variable que más determina la elisión del segmento. Por variantes, favorecen la elisión los contornos - $a d o$, -odo y, en menor medida, -oda, con índices por encima del 0.5 . En este grupo favorecedor de la elisión aparecen también las terminaciones - edo y -eda, pero sus bajos valores frecuenciales hacen que los datos en estos casos no se puedan considerar relevantes. Los madrileños rechazan claramente la elisión en el femenino -ada, así como los participios de la segunda y la tercera conjugación.

En cuanto a la categoría gramatical, la interjección, que ocupa la posición más favorecedora de la elisión, está representada en nuestro corpus 
fundamentalmente por joder, donde la elisión se explica por el carácter marcado discursivamente de este elemento -aparte de que su baja frecuencia obligue a que sus valores deban ser interpretados con cautela-. En un sentido similar, la presencia de los adverbios en el grupo favorecedor se explica por la inclusión, como ya vimos, de además y todavía, en los cuales la elisión puede obedecer a razones discursivas o de otro tipo. La categoría participio, que también favorece la elisión, obtiene un índice probabilístico muy diferente en el primer paso del análisis y en el último paso escalonado: es, por tanto, la categoría más permeable a la consideración individual o conjunta, lo que se explica por el hecho de que el entorno favorecedor - ado contrasta con el fuertemente restrictivo -ido, -ida. En posición favorecedora se encuentra también el adjetivo, mientras que el pronombre se ubica en una posición que podemos considerar neutra (este punto está marcado por el valor 0.5). Las categorías lingüísticas primarias, el nombre y el verbo, desfavorecen claramente la elisión, posiblemente porque en estos casos el fonema suele ser de carácter lexemático.

El equilibrio entre las restricciones de fidelidad y marcación explican lo que sucede en la variable seleccionada en el cuarto paso: el límite morfemático. En consonancia con lo que acabamos de señalar, el hecho de que la $d$ forme parte del morfema favorece con claridad la elisión, mientras que la retrae el que la dental se halle en el lexema. La pérdida de la $d$ en este caso podría influir en la identificación de la unidad, por lo que tiende a conservarse (marcación de fidelidad); en el morfema, por el contrario, la elisión no dificulta el reconocimiento de la unidad y facilita la pronunciación (restricción de marcación). 
El discurso no técnico es el más habitual en las entrevistas semidirigidas que componen el discurso, por lo que en este tipo de texto no se favorece la elisión. Es coherente que la mayor atención que exige el discurso metalingüístico retraiga la pérdida del segmento.

El hecho de que sea la fase final de la entrevista, como vimos en el análisis bivariante, la que más propicie la elisión no resulta extraño si se tiene en cuenta que en esta fase el hablante suele encontrarse en una situación más relajada y produce el estilo de habla menos formal de los obtenidos en la entrevista.

En cuanto a los tipos de discurso, todos ellos se sitúan cerca del punto neutro 0.5 , es decir, ninguno favorece ni desfavorece con claridad la elisión. Esta es algo más frecuente en el discurso dialógico y en el descriptivo, quizá porque en ellos el hablante preste menor atención a su discurso, y es menos frecuente en el discurso explicativo y argumentativo. En general, podría decirse que estos dos tipos de discurso exigen una mayor atención del hablante a su propio discurso, especialmente cuando el hablante ha de dar opiniones. No obstante, hay que tener en cuenta también la posible incidencia de la ubicación del tipo de discurso dentro de la entrevista.

Las palabras bisílabas favorecen la elisión en mayor medida que las trisílabas o polisílabas. Este hecho, que parece ir en contra de la restricción de fidelidad en la medida en que al desaparecer un elemento la unidad léxica se hace menos reconocible (véase $\$ 2.2 .1$ ), posiblemente se explique por la importancia cuantitativa que la elisión en todo y nada representa respecto a la suma total de las elisiones dentro del subgrupo de las bisílabas. 
Respecto a la edad, apenas hay diferencias entre las dos generaciones extremas: los de la última generación tienden ligeramente a elidir, mientras que los de la primera se ubican en el punto neutro. La segunda generación es la que presenta un comportamiento más divergente, patrocinando claramente las soluciones normativas.

\subsubsection{Análisis de regresión (entorno -ado)}

El análisis escalonado ha dejado apenas un manojo de variables como incidentes en la elisión de la dental. Debemos considerar este hecho como esperable, pues, dado que la terminación - ado favorece claramente la elisión, los factores que la determinan son muy pocos, en este caso la categoría léxica, la fase de la interacción, la difusión léxica y la relación de proximidad entre el entrevistador y el entrevistado. ${ }^{16}$ Además, algunas de las variantes de las variables seleccionadas presentan unos valores frecuenciales muy bajos, lo que disminuye su capacidad explicativa.

16 Hay que tener en cuenta, no obstante, que para la elaboración de este corpus había sido previamente necesaria la restricción de muchas variables, como vocal previa y posterior, límite morfemático, posición del acento y otras. 
Tabla 8. Jerarquía de variables en la elisión de /d/ (Entorno -ado)

\begin{tabular}{llrlll}
\hline \multicolumn{1}{c}{ Rango y variable } & \multicolumn{1}{c}{ Variantes } & $\boldsymbol{N}$ & $\boldsymbol{f}$ & $\mathbf{P}_{\text {1 nivel }}$ & $\mathbf{P}_{\text {escal. }}$ \\
\hline 1. Categoría léxica & No marcado & 496 & 55.8 & 0.508 & 0.508 \\
Raz. ver.= -615.969; $\mathrm{P}=0.002$ & Marcado & 2 & 14.3 & 0.120 & 0.124 \\
2. Fase de la interacción & Final & 186 & 61.8 & 0.567 & 0.578 \\
Raz. ver.= -609.446; $\mathrm{P}=0.003$ & Intermedia & 168 & 56.2 & 0.510 & 0.506 \\
& Inicial & 144 & 47.5 & 0.424 & 0.416 \\
3. Difusión léxica & Quedar & 13 & 92.9 & 0.912 & 0.920 \\
Raz. ver.=-604.618; $\mathrm{P}=0.005$ & Resto & 485 & 54.6 & 0.491 & 0.490 \\
4. Tenor y proximidad & Desconocidos & 479 & 56.5 & 0.514 & 0.516 \\
Raz. ver.=-598.225; $\mathrm{P}=0.005$ & Conocidos & 8 & 36.4 & 0.318 & 0.308 \\
& Amigos o parientes & 11 & 33.3 & 0.290 & 0.251 \\
\hline
\end{tabular}

El carácter no marcado del término favorece ligerísimamente la eliminación de la dental, mientras que se retiene cuando el término tiene algún tipo de marca (extranjerismo, tecnicismo, etc.), pero debe notarse, no obstante, que solo dos casos corresponden al segundo grupo. La segunda variable en orden de importancia vuelve a ser la fase de la interacción y aquí, igual que en el entorno general, la probabilidad de elisión en este entorno va aumentando a medida que avanza la entrevista, aproximándose así a los estilos más informales. En la variable Difusión léxica solo se encuentran dos variantes: quedar y el resto; la primera favorece la eliminación en el participio (quedado > quedao). Por último, en el corpus el tipo de relación más frecuente entre los interlocutores es la que surge directamente del desarrollo de la entrevista, que no se conociesen previamente, lo que explica que la variante "desconocidos" obtenga un peso prácticamente coincidente con la probabilidad general de elisión. 


\section{Conclusiones generales}

En el barrio de Salamanca, la dental en posición de ataque silábico es una variable estable, con un índice bajo de actividad en su desarrollo lingüístico. La estabilidad que la variable ha mantenido a lo largo de los siglos ha resultado en un equilibrio de fuerzas entre el prestigio abierto y el encubierto, entre la influencia de la lengua estándar y la de los valores locales que mantienen rasgos del habla coloquial. Como preveía la hipótesis 1 , los madrileńos de esta parte de la ciudad se decantan por las realizaciones conservadoras de la dental, de acuerdo con los patrones fónicos del prestigio oficial o abierto.

El comportamiento de hombres y mujeres es revelador en este sentido pues, como preveía la hipótesis 2 , los hombres se identifican con las variantes con prestigio encubierto (elisión), mientras que las mujeres se decantan por las soluciones con prestigio abierto (conservación de la dental).

Pero además de estos, hay otros aspectos poco claros en relación a los mecanismos que condicionan este cambio: ¿se trata de un cambio fónico regular o de un cambio por difusión léxica?, ¿la elisión se difunde gradualmente afectando a los sonidos o a las palabras? El análisis ha mostrado la mayor relevancia de los factores lingüísticos sobre los socioestilísticos (hipótesis 3) y ha explorado la posibilidad de que la elisión estuviera asociada a palabras de uso frecuente en el discurso cotidiano. Sin embargo, las elisiones no se producen nunca en las palabras "muy frecuentes", sino que están condicionadas por el contexto fónico: la posición del acento en la sílaba que precede a la dental, la estructura acentual de la palabra y el entorno vocálico previo y posterior. 
Además, la lenición de la obstruyente oclusiva está sujeta a restricciones gramaticales como la categoría (las elisiones se dan en participios y adjetivos) o la funcionalidad (la dental se elide solo si no establece diferencias semánticas o categoriales). Esta caracterización de las restricciones lingüísticas del cambio no se atiene a lo previsto por la hipótesis 4: en esta comunidad la innovación no responde al mecanismo de difusión léxica, sino que avanza siguiendo la secuencia característica de un cambio fónico regular.

Aunque la innovación tiene poca actividad, en su estratificación por grupos de edad puede verse que la evolución de la elisión en el barrio de Salamanca tiene forma de V: la alta frecuencia con que se registra entre los hablantes mayores, se retrae en el paso de la tercera a la segunda generación para volver a cobrar vitalidad entre los jóvenes, quienes la adoptan en niveles superiores a los de sus abuelos. La difusión intermitente o no lineal de los procesos lingüísticos es una característica constante de la evolución lingüística. En el barrio de Salamanca se retoma la pronunciación innovadora que era característica de los mayores pero cambió en la segunda generación, más conservadora. Para entender estos datos hay que imaginar que en algún momento del pasado muchas variedades del español experimentaron un debilitamiento de la dental que afectó a los sufijos gramaticales además de a las raíces, y que una parte de esa variación se ha mantenido estable a través de las generaciones, por lo que los contextos donde aún se pierde serían residuales, restos de un largo desarrollo histórico que puede reactivarse. ${ }^{17}$

17 Existen testimonios de pérdida de la dental en participios en el habla de Madrid desde principios del siglo XVIII (Lapesa 1980:389). 
Se concluye, entonces, que la dental madrileña es una variable sociolingüística bien asentada en la comunidad y no un nuevo cambio fónico en curso, como lo prueba su desarrollo como marcador lingüístico con estratificación social y estilística (hipótesis 6). Esta variable -junto a otraspermite a los madrileños marcar su discurso como más o menos formal: la pronunciación se torna más conservadora en registros formales, mientras que la elisión aumenta en contextos de informalidad. En el corpus del barrio de Salamanca, su valor como marcador se manifiesta en la mayor frecuencia que la elisión va alcanzando a medida que avanza la entrevista y aumenta la informalidad de la situación.

Aunque en términos generales estamos ante un cambio fónico regular, estable o poco activo, el corpus oral del barrio de Salamanca revela una línea de desarrollo mucho más dinámica en el entorno restringido -ado, donde la dental se elimina en el 55\% de los casos frente al 14\% del entorno general, lo que confirma la hipótesis 5 .

La disparidad de frecuencias entre el contexto general y el restringido favorece el uso de la variable en la comunidad como marcador, pues resulta llamativo el elevado número de elisiones en -ado en una comunidad particularmente conservadora en el plano fónico. Las preguntas que se plantearon a continuación fueron: ¿de dónde procede el cambio?, ¿qué comunidades de habla o qué referentes sociales imitan los hablantes del barrio de Salamanca cuando deciden incorporar esta innovación en su habla?, ¿qué modelos sociales tratan de imitar sus líderes?

El análisis del cambio en el entorno -ado muestra una estratificación sociolingüística distinta de la que manifiesta en el entorno general, lo que significa que la tendencia se ha modificado al extenderse una valoración 
positiva de la elisión, que no solo se tolera, sino que se promueve en este entorno restringido.

En el conjunto de la comunidad, los menores de 55 años se decantan por la elisión en -ado en un momento en que la tendencia general en la comunidad era conservadora por influencia de la norma culta. El cambio de dirección del proceso está muy claro en el paso de la tercera a la segunda generación, pues si los hombres mayores de 55 años eran más innovadores que las mujeres de su edad, el patrón cambió en la siguiente generación (35-54 años), pasando las mujeres a liderar este proceso y situándose por delante de los hombres como agentes de la innovación. El análisis ha permitido observar matizadamente el proceso del cambio, mostrando cómo, dentro del grupo femenino, el subgrupo de las universitarias promueve la elisión mientras que las mujeres de los niveles bajos de instrucción adoptan soluciones normativas. Las razones de este comportamiento, a priori poco esperado, deben relacionarse con los cambios sociales que afectaron a las mujeres en la sociedad española a mediados de la década de los 70 del pasado siglo y, en concreto, al mayor acceso a la instrucción y a la vida laboral que han tenido las mujeres de esa segunda generación.

El análisis sociolingüístico de los comportamientos individuales del barrio arroja alguna luz sobre los modelos que están operando en la mente de los hablantes para favorecer el cambio de patrón, lo que podría suponer un movimiento de convergencia con las hablas castellanas septentrionales, especialmente con el castellano hablado en la región vasco-hablante (hipótesis 7). En esa región se utiliza un castellano vasco con rasgos específicos, uno de los cuales es la tendencia a la pérdida $\mathrm{de} / \mathrm{d} /$ intervocálica en -ado > -ao / -au: sentau 'sentado'. Aunque la elisión en -ado no se da 
solamente en el castellano de la zona vasca, allí es la pronunciación más común, acompañada regularmente por el cierre de /o/ en [u], que muy frecuentemente se pronuncia formando diptongo con la vocal precedente (Oñederra 2007:1106).

La elisión también es característica del castellano manchego (Moreno 2009:143) -donde es de origen andaluz- pero allí las vocales no experimentan, al menos con tanta intensidad, el cierre y diptongación que distingue el castellano de los vascos, entre quienes la innovación estaría en una etapa más avanzada, con alteraciones vocálicas casi generales en toda la comunidad. ${ }^{18}$

El análisis individual de los hablantes que componen la muestra en el barrio de Salamanca ha permitido confirmar, de forma muy clara en algunos casos, la influencia que ejerce el habla de los vascos y sus costumbres sobre algunos madrileños. Concretamente, algunas mujeres declararon afición y querencia por el País Vasco, región a la que decían viajar todos los años para veranear. ${ }^{19}$ Estas hablantes manifestaron claramente su adhesión a las costumbres del norte, evidenciada en la pronunciación, y muy específicamente en la elisión de la obstruyente dental sonora y en la diptongación de las vocales que quedan en contacto tras la desaparición de la consonante.

18 Un estudio realizado por Etxebarria (2000) en Bilbao matiza que aunque la diptongación decreciente es una solución muy común, no es general en toda la ciudad (apud Etxebarria 2007:43).

19 San Sebastián ha sido tradicionalmente ciudad de veraneo de la alta burguesía madrileña. 


\section{BibLIOGRAFÍA}

Alba, Orlando, 1999. "Elisión de la/d/intervocálica postónica en el español dominicano.” En Eduardo Ferastieri, Julia Cardona, Humberto López Morales, Amparo Morales de Walters (coords.), Estudios de lingüistica hispánica: homenaje a Maria Vaquero, San Juan: Universidad de Puerto Rico, pp. 3-21.

Alonso, Matilde y Elies Furió, 2007. "El papel de la mujer en la sociedad española", Grup d'Investigació Economia, treball i territorio, no 19. $<$ http://hal.archives-ouvertes.fr/docs/00/13/36/74/PDF/El_papel_de_ la_mujer_en_la_sociedad_espanola.pdf>[Consultado el 3/4/2014]

Eckert, Penelope, 2009. "Three Waves of Variation Study: The emergence of meaning in the study of variation", <http://www.stanford.edu/ - eckert/PDF/ThreeWavesofVariation.pdf> [Consultado el 30/05/2011]. Etxebarria Arostegui, Maitena, 2007. "Sociolinguistics of Spanish in the Basque Country and Navarre". International Journal of the Sociology of Language 184, pp. 37-58.

Gómez Molina, José Ramón y Ma Begoña Gómez Devis, 2010. "Mantenimiento y elisión de la /d/ intervocálica en el español de Valencia". Verba 37, 89-122.

Gómez Molina, José Ramón, 2013. "Interacción de factores internos y externos en la pronunciación de la /d/ intervocálica”. En José Ramón Gómez Molina (ed.), El español de Valencia. Estudio sociolingüistico. Berna: Peter Lang, 31-68.

Gómez Molina, José Ramón, Isabel Molina y Florentino Paredes, 2012. "La variación de la -/d/- intervocálica en comunidades de habla con- 
servadoras de Espańa: los casos de Madrid y Valencia”. En Ana Ma Cestero, Isabel Molina y Florentino Paredes (eds.), La lengua, lugar de encuentro. Actas del XVI Congreso Internacional de la Asociación de Lingüistica y Filología de la América Latina (Alcalá de Henares, 6-9 junio de 2011). Alcalá de Henares: SPP Universidad Alcalá, pp. 1975-1986. Labov, William, 2001. Principles of Linguistic Change, vol 2: Social Factors. Oxford \& Cambridge: Blackwell. [Trad. al español de Pedro Martín Butragueño (2006), Principios del cambio lingüístico. Vol. 1: Factores Sociales. Madrid: Gredos]

Laorden, Ángeles y Pilar Giménez, 1978. "La mujer en la universidad espańola”. Papers: Revista de Sociología 9, pp. 73-88.

López de la Cruz, Laura, 2001. "La presencia de la mujer en la universidad española" <http://es.scribd.com/doc/208338903/Dialnet-LaPresenciaDeLaMujerEnLaUniversidadEspanola-2480643-2 [Consultado el 01/04/2014]

Lapesa, Rafael, 1980. Historia de la lengua española, 8. ${ }^{a}$ ed. Madrid: Gredos.

Martín Butragueño, Pedro, 2002. Variación lingüistica y teoría fonológica. México: El Colegio de México.

Martín Butragueño, Pedro, 2006. "Líderes lingüísticos en la ciudad de México”. En Pedro Martín Butragueño (ed.), Estudios de variación y cambio, México: El Colegio de México, pp. 185-208.

Martín Butragueño, Pedro, 2014. "Obstruyentes oclusivas: tensión y relajamiento como motor de la variación fónica. Notas sobre la variación en las oclusivas orales". En Fonología variable del español de México. Vol. I: procesos segmentales, México: El Colegio de México, pp. 245-272. 
Molina, Isabel, 2006. "Innovación y difusión del cambio lingüístico en Madrid". Revista de Filología Española 86 (1), pp. 127-149.

Molina, Isabel, 2011. "Un cambio fónico en las hablas rurales madrileñas: la consonante dental intervocálica”. En M. Nevaci (ed.), Studia linguistica et philological. Omagiu profesorului Nicolae Saramandu. Bucarest: Ed. Universitatii din Bucuresti.

Molina, Isabel, 2013. "Yeísmo madrileño y convergencia dialectal campo/ ciudad”. En Rosario Gómez e Isabel Molina (eds.), Variación yeista en el mundo hispánico. Madrid/Francfurt: Iberoamericana/Vervuert, pp. 93-111.

Moreno, Francisco, 2006. La lengua española en su geografía. Madrid: Arco/Libros.

Moreno, Francisco, Ana Ma Cestero, Isabel Molina y Florentino Paredes, 2000. "La sociolingüística de Alcalá de Henares en el Proyecto para el Estudio Sociolingüístico del español de España y América”. Oralia 3, pp. 149-168.

Moya, Juan Antonio, Emilio J. García Wiedemann, Esteban T. Montoro, Marcin Sosinsky, Ma Concepción Torres, Francisca Pose Furest y Elisabeth Melguizo, 2012. "La /d/ intervocálica en Granada: factores lingüísticos y sociales”. Español hablado. Estudios sobre el corpus PRESEEA-Granada. Varsovia: Instituto de Estudios Ibéricos e Iberoamericanos.

Oñederra, Miren Lourdes, 2007. "El español en contacto con otras lenguas: español-vasco", en Rafael Cano (coord.), Historia de la lengua española. Barcelona: Ariel, pp. 1103-1115. 
Samper Padilla, José Antonio, Clara E. Hernández, Magnolia Troya, Ana Ma Pérez, y Marta Samper, 2010. "Un estudio de variación fonética en el marco del PRESEEA: realizaciones de /d/ entre los hablantes de nivel universitario de Las Palmas de Gran Canaria”. Lingüistica Española Actual 32, pp. 5-34.

Samper Padilla, José Antonio, 2011. "Elisión de /d/ en los niveles de estudios primario y universitario de Las Palmas de Gran Canaria. Comparación con otras comunidades de habla”, en José Joaquín Bustos Tovar, Rafael Cano, E. Méndez y A. López (coords.), Sintaxis y análisis del discurso hablado en español. Homenaje a Antonio Narbona, vol I. Sevilla: Universidad de Sevilla, pp. 409-424.

Samper Padilla, José Antonio, Clara E. Hernández Cabrera, Magnolia Troya Déniz, Ana Ma Pérez Martín y Marta Samper Hernández, 2011. "Estudio sociolingüístico de la variación de -/d/- en la ciudad de Las Palmas de Gran Canaria”. Comunicación presentada en el XVI Congreso Internacional de la ALFAL, Alcalá de Henares.

Villena Ponsoda, Juan Andrés; Francisco Díaz Montesinos, Antonio M. Ávila Muñoz y M. ${ }^{a}$ Cruz Lasarte Cervantes, 2011. "Interacción de factores fonéticos y gramaticales en la variación fonológica: la elisión de /d/ intervocálica en la variedad de los hablantes universitarios en la ciudad de Málaga”. En Yolanda Congosto y Elena Méndez (eds.), Variación lingüistica y contacto de lenguas en el mundo hispánico. In memoriam Manuel Alvar, Madrid/Francfurt: Iberoamericana/Vervuert, pp. 311-359.

Villena Ponsoda, Juan, 2012. "Estatus, red e individuo. Fundamentos del análisis escalonado de la variación lingüística. Elisión de /d/ en el español de Málaga”. Actas del X Congreso de Lingüistica General de Zaragoza. 